\title{
Decentralized Matching Markets with Endogenous Salaries*
}

\author{
Hideo Konishi ${ }^{\dagger} \quad$ Margarita Sapozhnikov ${ }^{\ddagger}$ \\ January 2, 2008
}

\begin{abstract}
In a Shapley-Shubik assignment problem with a supermodular output matrix, we consider games in which each firm makes a take-it-orleave-it salary offer to one applicant, and a match is made only when the offer is accepted by her. We consider both one-shot and multistage games. In either game, we show that there can be many equilibrium salary vectors which are higher or lower than the minimum competitive salary vector. If we exclude artificial equilibria, applicants' equilibrium salary vectors are bounded above by the minimal competitive salary vector, while firms' equilibrium payoff vectors are bounded below by the payoff vector under the minimum competitive salary vector. This suggests that adopting the minimum competitive salary vector as the equilibrium outcome in decentralized markets does not have a strong justification. JEL classification numbers: C71, C72, C78, J20, J30
\end{abstract}

${ }^{*}$ We thank Takashi Hayashi, Fuhito Kojima, Jihong Lee, Al Roth, Utku Ünver, and participants of the Midwest Economic Theory Conference in Lawrence, Kansas, and the seminars at Osaka and Hitotsubashi Universities for their helpful comments. Comments, encouragements, and constructive criticisms from two anonymous referees were particularly helpful. All errors are, of course, our own.

${ }^{\dagger}$ Corresponding Author: Department of Economics, Boston College, 140 Commonwealth Avenue, Chestnut Hill, MA 02467, USA. hideo.konishi@bc.edu

${ }^{\ddagger}$ CRA International, John Hancock Tower, 200 Clarendon Street, T-33 Boston, MA 02116-5092, USA. msapozhnikov@crai.com 


\section{Introduction}

As is described in Roth (1984), the centralized matching procedure in the US medical resident market - the National Residency Matching Program (NRMP) - has been a tremendous success. NRMP uses the deferred-acceptance matching algorithm developed in Gale and Shapley (1962) with a salary vector chosen by hospitals prior to the matching procedure in order to assign senior medical students to residency programs at participating hospitals. The introduction of NRMP helped reduce the early contract craze and last-minute congestion that resulted under the decentralized system, and the NRMP participation rate by both students and hospitals has been very high.

In 2002, however, a lawsuit against teaching hospitals and NRMP was filed alleging that the system violated federal antitrust law (in that, for example, it restrained competition). This lawsuit could have had a significant impact on the medical market: one possible consequence was abandonment of the NRMP and other medical matching programs. ${ }^{1}$

Recently, Bulow and Levin (2006) set up an interesting matching model that can compare the centralized matching mechanism that has characteristics of NRMP with a decentralized market. Bulow and Levin (2006) employ a simplified version of the assignment model in Shapley and Shubik (1972), and consider a two-stage game. In the first stage, hospitals simultaneously decide salaries, and in the second stage the Gale-Shapley deferred-acceptance matching algorithm takes place, using the preferences of hospitals and residents generated by the price vector determined in the first stage. Thus, their game mimics the matching program of the NRMP. Bulow and Levin (2006) characterize a mixed-strategy equilibrium of the game, and compare the expected equilibrium salary of each resident in the game with her minimum competitive salary. The minimum competitive salary (vector) is the lowest market equilibrium salary vector under which the surplus-maximizing assignment of hospitals and residents is stable (Shapley and Shubik 1972). The main finding of their paper is that under the centralized system, salaries and applicants' payoffs are more suppressed than they are under the decentralized system.

Although the result of Bulow and Levin (2006) appears to suggest the benefits of a decentralized market, ${ }^{2}$ the notion of the minimum competitive

\footnotetext{
${ }^{1}$ This lawsuit was dismissed in 2004 following the president's signing a rider law (the Pension Funding Equity Act of 2004) exempting NRMP from antitrust lawsuits.

${ }^{2}$ Bulow and Levin (2006) caution that their result does not directly indicate that NRMP
} 
salary does not really fit with an equilibrium outcome of a decentralized resident-hospital matching market. Since each resident is a heterogeneous commodity, the minimum competitive salary can be attained as a result of a Vickrey auction in the centralized multi-object auction market. However, this mechanism clearly also requires a centralized auction market. It is not clear what kind of decentralized salary vector emerges under a decentralized market given the typical bilateral job offers in the resident-hospital market.

In this paper, we analyze equilibria of noncooperative games that describe decentralized markets using the Shapley-Shubik assignment model. Following Bulow and Levin (2006), we assume that the output matrix is supermodular (slightly more general than the one in Bulow and Levin), and we consider games in which each firm chooses an applicant and makes a take-it-or-leaveit salary offer and a match is made only when the offer is accepted by the applicant. ${ }^{3}$ We consider both one-shot and multistage games. Although these games are too simplistic to describe to be taken to real-world market institutions, they can be regarded as a first step in an attempt to analyze the equilibrium salary vectors in a decentralized labor market for entry-level professionals such as the one for medical interns.

The results of the paper are as follows. In a one-shot simultaneous move game, in many cases, a mixed strategy equilibrium makes more sense. In all mixed-strategy equilibria, the highest possible realization of a salary vector is the minimum competitive equilibrium salary vector: i.e., applicants' expected utilities are lower than the minimum competitive salaries. On the other hand, firms get exactly the same expected payoffs under the minimum competitive salary vector as they do in all mixed-strategy equilibria (Proposition 1). In contrast, a pure strategy equilibrium may not exist (Proposition 2 ), and even if it does, it is somewhat artificial and weakly dominated, and the equilibrium vanishes if there is a small cost attached to making offers. However, when there exists a pure strategy equilibrium, there are many equi-

suppresses the wages of medical residents, since NRMP can use enormous amounts of information nationally whereas a decentralized system tends to match agents locally.

${ }^{3}$ We adopt a setup in which firms make only a limited number of offers (constrained by the number of slots) to applicants, following the literature on timing of transactions and congestion in market clearing (Roth and Xing, 1994, Niederle and Roth, 2007, and Niederle, Roth and Ünver, 2006). As examples of those markets, Roth and Xing (1994) list many entry-level professional labor markets including the US medical intern markets mentioned in Roth (1984) and Bulow and Levin (2006), and the adopted setup applies to these markets. The "take-it-or-leave-it" offer assumption is certainly for simplification. This assumption is also commonly made in the literature. 
libria, and pure strategy equilibrium salaries can be higher or lower than the minimum competitive salaries (Example 2).

In a multistage model, we show that if each offer has no deadline, that is, if each offer is valid until it has been accepted or rejected (an "open offer" assumption $),{ }^{4}$ there is a stationary Markov perfect equilibrium that achieves the minimum competitive salary vector (Proposition 3). This equilibrium actually attains the highest salary vector among all stationary Markov perfect equilibria in pure strategies if we do not allow rejections on the equilibrium path (Proposition 4). ${ }^{5}$ If rejections are allowed to occur on the equilibrium path, then there are many equilibria, and an applicant may get a higher salary than the minimum competitive salary (Example 4). However, these rejections on the equilibrium paths have an artificial and pathological nature (a firm has an incentive to give a candidate an unreasonable offer in order to get a rejection, since the rejection changes the equilibrium path in the firm's favor). ${ }^{6}$

These results seem to indicate the following. First, in decentralized markets, if artificial equilibria are allowed, then there are many equilibrium salary vectors that can be higher or lower than the minimum competitive salary vector. Second, if we exclude artificial equilibria, then the minimum competitive salary vector is the best-case scenario for applicants in the decentralized market. That is to say, the reference salary vector adopted by Bulow and Levin (2006) for the decentralized market outcome might not have a strong justification, and could be regarded as rather optimistic.

The rest of the paper is organized as follows. In the rest of the introduction, we briefly discuss the relevant literature. Section 2 presents the

\footnotetext{
${ }^{4} \mathrm{An}$ offer is called open if the offer is valid until it has been accepted or rejected by the applicant who received it. In contrast, an offer is called exploding if an applicant who receives it needs to either accept or reject it immediately, and she will not be able to receive another offer from the same firm in future if she rejects it. In the literature of congestion in market clearing, using open offers seems to make the market more efficient than using exploding offers, so we are adopting a conservative assumption.

${ }^{5}$ There are stationary Markov perfect equilibria with lower salaries including a zerosalary vector without rejections on the equilibrium path (when the number of firms is less than the one applicant).

${ }^{6}$ Although these equilibria are somewhat artificial, they are robust equilibria in the sense that their strategies are not weakly dominated and they survive small costs of making offers. Thus, one way to interpret this result is that without further restrictions on strategies, many different outcomes can be supported as stationary Markov perfect equilibria even under the open offer assumption.
} 
Shapley-Shubik model with a supermodular and increasing output matrix. In Section 3, a simultaneous-move game is analyzed. In Section 4, a multistage game with open offers is analyzed. Section 5 concludes, and Section 6 collects all proofs.

\subsection{Literature Review}

The conclusion of this paper, that the minimum competitive salary vector may not be a good approximation of equilibrium outcome in decentralized markets, can be interpreted as at odds with the result of Bulow and Levin (2006), that the centralized matching program tends to suppress applicants' salaries, since they use the minimum competitive salary vector as the decentralized market outcome. In contrast, Kojima (2006) and Niederle (2006) question the policy implications of Bulow and Levin (2006) regarding the NRMP from different viewpoints. Keeping the minimum competitive salary as the reference for decentralized markets, they modify the centralized matching market in a way that is more appropriate to the NRMP. Kojima (2006) extends the Bulow-Levin model to a many-to-one matching problem, and presents an example in which the unique equilibrium salary vector dominates the minimum competitive salary vector. Niederle (2006) notes that the NRMP allows for ordered contracts, or reverting positions. Programs that try to fill a position under a certain contract can, if they do not find a suitable candidate, change that contract to one under a different contract. Given this feature, she finds that there is a pure strategy Nash equilibrium in which the equilibrium salary vector coincides with the minimum competitive salary vector when hospitals use ordered contracts. Thus, these papers and the current paper may complement each other.

There is an extensive literature on the labor market with frictions. ${ }^{7}$ Shimer (2005) in particular is related to the static model of the current paper. He considers a model in which there are heterogeneous types of firms and applicants, and there is a continuum of clones in each type. In his setup, each individual firm posts salaries for all types of applicants simultaneously, then applicants apply for posted positions with symmetric mixed strategies. ${ }^{8}$ Each

\footnotetext{
${ }^{7}$ See a nice survey by Rogerson, Shimer and Wright (2005).

${ }^{8}$ Shimer (2005) calls it an "anonymity" restriction which means that identical type workers use identical mixed strategies in the second stage of the game. Thus, identical type workers apply for each individual firm of an identical type with an equal likelihood. That is, Shimer concentrates on symmetric strategies within identical types of workers.
} 
individual firm chooses one from its applicant pool. Rejected applicants and (ex post) no-applicant firms are unmatched. With this setup, Shimer (2005) proves that there is a unique equilibrium that achieves constrained efficiency. ${ }^{9}$ Moreover, Shimer finds an imperfectly assortative matching as the unique equilibrium outcome in the case of multiplicative output matrices. In our static game, there are also frictions due to the usage of mixed strategies, and there is ex post mismatch in otherwise assortative matching. However, there are differences. First, whereas in Shimer (2005) the source of inefficiency is the social planner's technology constraint motivated by large markets, the inefficiency in our match equilibrium comes from each firm's exercising its monopoly power and the resulting strategic interactions. ${ }^{10}$ Second, more importantly, in our model, we assume that firms make offers to applicants and applicants accept or reject the offers. This setup is more appropriate to describing professional labor markets with heterogeneous applicants, such as the market for medical interns (Roth, 1984, and Bulow and Levin, 2006). Roth and Xing (1994), Niederle and Roth (2007), and Niederle, Roth, and Ünver (2006) discuss how such markets for professionals work and adopt a setup in which firms make one offer at each time in one-to-one matching problems. The most familiar example may be the market for fresh Ph.D. economists. In contrast, Shimer's wage posting game is probably more appropriate to describing standard large labor markets with less heterogeneous applicants, since wage posting make more sense with many anonymous applicants within the same type. ${ }^{11}$

Related to our dynamic model, there are papers that formalize decentralized markets in more realistic ways than ours. Roth (1984) describes how the

Firms also do not distinguish individual workers of the same type (offer the same wages). In contrast, he does not impose a symmetry restriction on identical firms' strategies: instead, he proves that identical firms play identical strategies in the equilibrium.

${ }^{9}$ Frictions are from coordination failure among workers. Shimer (2005) argues that in large market, it is natural to have coordination failures due to anonymity of participants.

${ }^{10}$ We thank one of the referees for making this insightful remark.

${ }^{11}$ If we apply Shimer's setup to our specialized professional labor market (i.e., one worker for each type), posting salaries for all types means posting salaries for all individual workers. (This case is the same as dropping "anonymity" among workers: workers are allowed to use asymmetric pure strategies.) It is almost obvious to see that, in such a case, there is a pure strategy subgame perfect equilibrium in which efficient matching is achieved with the minimum competitive salary vector. This may sound like a nice result, but a wage posting game may be less appropriate to describing a specialized labor market for professionals. 
decentralized market operated prior to the NRMP period. Due to a shortage of interns, hospitals attempted to finalize binding agreements with residents earlier than competitors. As a result, the date by which most contracts had been finalized crept forward (unraveling). To fix this coordination problem, the Association of American Medical Colleges (AAMC) prohibited early contracts prior to a certain date. Although this practice proved to be effective in resolving unraveling, it led to a new problem: a student who got an offer from one hospital would wait as long as possible before accepting the offered position in the hope of getting an offer from a preferable hospital. So, to speed up the matching process, deadlines for accepting offers became shorter and shorter, leading to exploding offers. From these observations, Roth and Xing (1994) formulate interesting multiperiod strategic models of bilateral matching markets with and without endogenous salaries. They show that all subgame perfect equilibria are inefficient due to inefficient unraveling. Recently, Niederle and Roth (2007) and Niederle, Roth, and Ünver (2006) set up multiperiod incomplete information models with fixed salaries, and analyze the conditions (market cultures and demand and supply conditions, respectively) under which unraveling can occur in equilibrium and thus result in inefficient outcomes. In the current paper, in contrast, we introduce neither inefficiency due to early contracting nor inefficiency due to exploding offers. We focus on equilibrium salaries by employing simplifying assumptions. A possible interpretation of our results in the multistage game (especially Example 4) is somewhat negative: even if there is no inefficiency due to early contracts or exploding offers, and even under perfect and complete information, there is a continuum of equilibrium salary vectors that can be above or below the minimum competitive salary vector, even after refining equilibria by imposing stationary Markov and weakly dominant restrictions on players' strategies, or by assuming that making offers is costly.

There are two other loosely related papers on the implementation of stable matching with endogenous salaries. Alcalde, Pérez-Castrillo, and RomeroMedina (1998) and Hayashi and Sakai (2004) investigate the implementability of the stable matching correspondence in a many-to-one job matching problem with a gross substitutable preference domain (Kelso and Crawford 1982). Alcalde, Pérez-Castrillo, and Romero-Medina (1998) show that a stable matching correspondence is implementable in a subgame perfect equilibrium when there are at least two firms. Hayashi and Sakai (2004), in contrast, show that the stable matching correspondence is the minimum Nashimplementable correspondence satisfying individual rationality and nondis- 
crimination. Our work differs from theirs in two ways. First, the domains of the problems are different. It may appear that a many-to-one matching model with gross substitutable preferences is more general than ours. However, since these papers allow each firm to make multiple offers simultaneously, firms make offers to all acceptable applicants under the "gross substitutability" assumption by Kelso and Crawford (1982). In contrast, in our model firms can make one offer each (at one time). Thus, there is an opportunity cost of making an offer to an applicant since a firm may miss the opportunity of hiring the second-best applicant by making an unsuccessful offer to the most preferable applicant. This congestion effect makes our problem very different from that of these two papers. Second, the purposes of these two papers is to implement all stable matchings (competitive salary vectors), whereas we are interested in one particular stable matching: the minimum competitive salary vector.

\section{The Shapley-Shubik Assignment Problem with Supermodular Output Matrix}

There are two disjoint finite sets of agents, applicants and firms, denoted by $A=\left\{a_{1}, \ldots, a_{m}\right\}$ and $F=\left\{f_{1}, \ldots, f_{n}\right\}$, respectively. We assume that each firm has exactly one position each.

The firm-applicant matching problem is described as an assignment model by Shapley and Shubik (1972). Each firm hires at most one applicant, and

the output that each pair of firms and applicants can produce is described in the following $n \times m$ output matrix:

$$
Y=\left(\begin{array}{cccc}
Y_{11} & Y_{12} & \cdots & Y_{1 m} \\
Y_{21} & Y_{22} & \cdots & Y_{2 m} \\
\vdots & \vdots & \ddots & \vdots \\
Y_{n 1} & Y_{n 2} & \cdots & Y_{n m}
\end{array}\right)
$$

where $Y_{i j}>0$ denotes the amount of output a firm-applicant pair $\left(f_{i}, a_{j}\right)$ can produce together. We assume that every argument of the matrix is positive. 
An assignment matrix is an $m \times n$ matrix

$$
X=\left(\begin{array}{cccc}
x_{11} & x_{12} & \cdots & x_{1 n} \\
x_{21} & x_{22} & \cdots & x_{2 n} \\
\vdots & \vdots & \ddots & \vdots \\
x_{m 1} & x_{m 2} & \cdots & x_{m n}
\end{array}\right)
$$

where (i) for each applicant $a_{j} \in A$ and for each firm $i \in F$, we have $x_{j i} \in$ $\{0,1\}$, and (ii) for each applicant $a_{j} \in A, \sum_{i=1}^{n} x_{j i} \leq 1$ and for each firm $f_{i} \in F, \sum_{j=1}^{m} x_{j i} \leq 1$. This matrix describes the matching between applicants and firms. An optimal assignment matrix $X^{*}$ is an assignment matrix that maximizes the total production of this industry:

$$
\sum_{i=1}^{n} \sum_{j=1}^{m} x_{j i}^{*} Y_{i j}=\max _{X} \sum_{i=1}^{n} \sum_{j=1}^{m} x_{j i} Y_{i j} .
$$

An outcome of the assignment problem is a list of an assignment and profit and salary vectors $(X, \boldsymbol{\pi}, \mathbf{s})$ such that $\boldsymbol{\pi}=\left(\pi_{1}, \ldots, \pi_{m}\right) \in \mathbb{R}_{+}^{m}, \mathbf{s}=$ $\left(s_{1}, \ldots, s_{n}\right) \in \mathbb{R}_{+}^{n}$, and $x_{i j}=1$ iff $\pi_{i}+s_{j}=Y_{i j}$ and $s_{j}=0$ for $a_{j} \in A$ with $\sum_{i=1}^{n} x_{i j}=0$ (zero salaries for applicants who are not assigned to any firm). An outcome of an assignment problem is stable if for any $f_{i} \in F$ and for any $a_{j} \in A, \pi_{i}+s_{j} \geq Y_{i j}$. If an outcome $(X, \boldsymbol{\pi}, \mathbf{s})$ is stable then $\mathbf{s}$ is said to be a competitive salary vector, and $\mathbf{s}^{*}$ is said to be the minimum competitive salary vector if $\mathbf{s}^{*}$ is a competitive salary vector, and $\mathbf{s}^{*} \leq \mathbf{s}^{\prime}$ holds for any competitive salary vector $\mathbf{s}^{\prime}$. The minimum competitive salary vector can be determined by a multi-object ascending price auction algorithm formulated by Demange, Gale, and Sotomayor (1986). Strict supermodularity and strict increasingness give us an explicit formula for the minimum competitive salary.

In this paper, we additionally assume that the output matrix is strictly supermodular if for any $f_{i} \in F$ and for any $a_{j} \in A$

$$
Y_{i j}-Y_{i j+1}>Y_{i+1 j}-Y_{i+1 j+1},
$$

and strictly increasing if for any $f_{i} \in F$ and for any $a_{j} \in A$

$$
Y_{i j}-Y_{i j+1}>0 \text { and } Y_{i j}-Y_{i+1 j}>0 .
$$


We assume that $Y$ is strictly supermodular and strictly increasing throughout the paper. ${ }^{12}$ These assumptions guarantee that there is a unique optimal assignment matrix $X^{*}$ that is assortative, i.e. $x_{i i}=1$ for any $i=\{1, \ldots, m\}$. The following lemma characterizes the minimum competitive salary vector.

Lemma 1. If the output matrix $Y$ is strictly supermodular and strictly increasing then the minimum competitive salary vector is $\mathbf{s}^{*}=\left(s_{1}^{*}, \ldots, s_{m}^{*}\right)$, where (i) $s_{j}^{*}=\sum_{j^{\prime}=j}^{n-1}\left(Y_{j^{\prime}+1 j^{\prime}}-Y_{j^{\prime}+1 j^{\prime}+1}\right)$ for any $j \leq n-1$ and $s_{j}^{*}=0$ for $j \geq n$ when $n \leq m$, and (ii) $s_{j}^{*}=Y_{m m}+\sum_{j^{\prime}=j}^{m-1}\left(Y_{j^{\prime}+1 j^{\prime}}-Y_{j^{\prime}+1 j^{\prime}+1}\right)$ for any $j \leq m-1$ and $s_{m}^{*}=Y_{m+1 m}$ when $n>m$.

\section{One-Shot Game}

Consider a one-shot game. Each firm $f_{i}$ decides which applicant to make an offer to, and how much salary to offer her. We assume that an offer is a take-it-or-leave-it offer. All firms make simultaneous offers, and applicants choose the best offer if they receive multiple offers. We assume the following tie-breaking rule: if an applicant $a_{j}$ receives offers from $f_{i}$ and $f_{i^{\prime}}$ with the same salaries $\left(i<i^{\prime}\right)$, then $a_{j}$ prefers $f_{i}$ to $f_{i^{\prime}}$. If an applicant accepts an offer a match is made. There is no aftermarket as in Shimer (2005). As we shall see below, a mixed-strategy equilibrium is more interesting in this game, so we will start with analyzing mixed-strategy equilibria.

Let $G=\left(G_{i j}\right)_{f_{i} \in F, a_{j} \in A}$ be a mixed-strategy profile, where $G_{i j}(s) \in[0,1]$ is the probability that $f_{i}$ offers a salary $s^{\prime} \leq s$ to applicant $a_{j}$. Let $\bar{s}_{i j}$ be the lowest upper bound of the support of $G_{i j}: \bar{s}_{i j} \equiv \min s_{i j} \in \mathbb{R}_{+}$subject to $G_{i j}\left(\bar{s}_{i j}\right)=G_{i j}(\infty)$, and let $\bar{s}_{j}=\max _{f_{i} \in F} \bar{s}_{i j}$. That is, $\bar{s}_{j}$ is the highest possible salary realization for applicant $a_{j}$ under a strategy profile $G$. Given a strategy profile $G$, let $w_{i j}(s)=\prod_{i^{\prime} \neq i}\left(1-\left(G_{i^{\prime} j}\left(\bar{s}_{j}\right)-G_{i^{\prime} j}(s)\right)\right)$. This function denotes $f_{i}$ 's winning probability of hiring $a_{j}$ by offering $s$ to $a_{j}$, since $G_{i^{\prime} j}\left(\bar{s}_{j}\right)-G_{i^{\prime} j}(s)$ is the probability that $f_{i^{\prime}}$ makes a better offer to $a_{j}$. Let $u_{i}(G)$ and $v_{j}(G)$ be the equilibrium payoff of $f_{i}$ and $a_{j}$, respectively $(i=1, \ldots, n$ and $j=$ $1, \ldots, m)$. The main result of this section is the characterization of mixedstrategy equilibria.

\footnotetext{
${ }^{12}$ The frequently used multiplicative output matrix and semi-multiplicative output matrix in Bulow and Levin (2006) satisfy both supermodularity and increasingness. However, note that for simplicity, we do not allow indifference (by assuming "strictness").
} 
Proposition 1. Suppose that $Y$ is strictly supermodular and strictly increasing, and that $n \geq 2$ and $m \geq 2$. In any mixed-strategy equilibrium $G$ in a one-shot game, we have: for all $i=1, \ldots, n$ and all $j=1, \ldots, m$, (i) $\bar{s}_{j}=s_{j}^{*}$ for all $j=1, \ldots, m$, (ii) $u_{i}(G)=Y_{i i}-s_{i}^{*}$ for all $i \leq \min \{n, m\}$ and $u_{i}(G)=0$ if $n>m$, and (iii) $v_{j}(G)<s_{j}^{*}$ for all $j \leq \min \{n-1, m\}$ and $v_{j}(G)=s_{j}^{*}=0$ for all $j>\min \{n-1, m\}$.

Since a realized outcome of the game may leave some firms and applicants unmatched under a mixed-strategy equilibrium, it may not be surprising that applicants' payoffs are lower than the minimum competitive salaries (result (iii)). However, it is interesting that the very best realization (with a zero measure) for each applicant is the minimum competitive salary (result (i)), and firms earn exactly the same expected profits as under a stable matching with the minimum competitive salary vector (result (ii)). That is, all costs of mismatch are levied on applicants in our game. To see what mixed-strategy equilibrium looks like, we provide a simple example.

Example 1. Consider the case where $m=n=3$.

$$
Y=\left(\begin{array}{lll}
Y_{11} & Y_{12} & Y_{13} \\
Y_{21} & Y_{22} & Y_{23} \\
Y_{31} & Y_{32} & Y_{33}
\end{array}\right)=\left(\begin{array}{lll}
9 & 6 & 3 \\
6 & 4 & 2 \\
3 & 2 & 1
\end{array}\right)
$$

In this example, we have a unique mixed-strategy equilibrium. By Proposition 1 , the upper bound vector $s^{*}=\left(s_{1}^{*}, s_{2}^{*}, s_{3}^{*}\right)=(3,1,0)$. Since each firm is indifferent between playing pure strategies that are supported by its mixed strategy, we have

$$
\begin{aligned}
& w_{11}\left(s_{1}\right)\left(9-s_{1}\right)=6 \\
& w_{21}\left(s_{1}\right)\left(6-s_{1}\right)=w_{22}\left(s_{2}\right)\left(4-s_{2}\right)=3 \\
& w_{31}\left(s_{1}\right)\left(3-s_{1}\right)=w_{32}\left(s_{2}\right)\left(2-s_{2}\right)=w_{33}\left(s_{3}\right)\left(1-s_{3}\right)=1
\end{aligned}
$$

Note that given $Y, f_{1}$ and $f_{2}$ have no incentive to make offers to $a_{2}$ or $a_{3}$, and to $a_{3}$, respectively. The equilibrium strategy profile $G$ that satisfies the above is as follows: ${ }^{13}$

\footnotetext{
${ }^{13}$ This equilibrium is found by a guess-and-verify method. Assume that $f_{3}$ does not
} 
- Firm $f_{1}$ makes an offer to $a_{1}$ only: $s_{1}=0$ with probability $\frac{1}{2}$, and $s_{1} \in(0,3]$ with density $\frac{3}{\left(6-s_{1}\right)^{2}}$.

- Firm $f_{2}$ makes an offer $s_{1} \in(0,3]$ to $a_{1}$ with density $\frac{6}{(9-s)^{2}}$, an offer $s_{2}=0$ to $a_{2}$ with probability $\frac{1}{6}$, and $s_{2} \in(0,1]$ with density $\frac{1}{(2-s)^{2}}$.

- Firm $f_{3}$ does not make an offer to $a_{1}$, makes an offer $s_{2} \in(0,1]$ to $a_{2}$ with density $\frac{3}{(4-s)^{2}}$, and an offer $s_{3}=0$ to $a_{3}$ with probability $\frac{3}{4}$.

Given these strategies, we can calculate the expected utility of applicants. First, by Proposition 1, firms get the same expected payoff as they do under the minimum competitive equilibrium; thus $u(G)=(6,3,1)$. Second, given strategy profile $G$, firm $f_{i}$ 's winning probability $w_{i j}\left(s_{j}\right)$ when it makes an offer with salary $s_{j}$ to $a_{j}$ is as follows:

$$
\begin{aligned}
& w_{11}\left(s_{1}\right)=\frac{6}{9-s_{1}}, \\
& w_{21}\left(s_{1}\right)=\frac{3}{6-s_{1}}, \\
& w_{22}\left(s_{2}\right)=\frac{3}{4-s_{2}}, \\
& w_{32}\left(s_{2}\right)=\frac{1}{2-s_{2}} .
\end{aligned}
$$

Thus, we have

$$
\begin{aligned}
v_{1}(G) & =\int_{0}^{3} s_{1} \frac{3}{\left(6-s_{1}\right)^{2}} \frac{6}{9-s_{1}} d s_{1}+\int_{0}^{3} s_{1} \frac{3}{\left(9-s_{1}\right)^{2}} \frac{3}{6-s_{1}} d s_{1} \\
& =1.0478
\end{aligned}
$$

make an offer to $a_{1}$. Then, $f_{1}$ 's rival is only $f_{2}$. Then, $w_{11}\left(s_{1}\right)$ is dictated by $f_{2}$ 's mixed strategy. Thus, $f_{2}$ 's density function of making an offer to $f_{1}$ is $\frac{3}{\left(6-s_{1}\right)^{2}}$, since the support of $f_{2}$ 's strategy is $(0,3]$ by Claims 1,2 and 4 in the proof of Proposition 1. Similarly, each firm's density function of making an offer to each applicant can be calculated. By our tie-breaking rule, $f_{2}$ and $f_{3}$ do not play $s_{1}=0$ and $s_{2}=0$, respectively. Thus, $f_{1}$ and $f_{2}$ are the only ones that play $s_{1}=0$ and $s_{2}=0$, respectively. These pin down the equilibrium strategies. Instead, if we assume that $f_{3}$ makes an offer to $a_{1}$ with a positive probability, we reach a contradiction. Thus, we have a unique mixed-strategy equilibrium in this example. 


$$
\begin{aligned}
& v_{2}(G)= \int_{0}^{1} s_{2} \frac{1}{\left(2-s_{2}\right)^{2}} \frac{3}{4-s_{2}} d s_{2}+\int_{0}^{1} s_{2} \frac{3}{\left(4-s_{2}\right)^{2}} \frac{1}{2-s_{2}} d s_{2} \\
&= 0.3918 \\
& v_{3}(G)=0
\end{aligned}
$$

The resulting expected salary vector is $v(G)=(1.0478,0.3918,0)$. By summing up all the payoffs, we obtain

$$
\sum_{i=1}^{3} u_{i}(G)+\sum_{j=1}^{3} v_{i}(G)=11.4396 .
$$

Under the minimum competitive equilibrium salaries, the total surplus is $\sum_{i=1}^{3} Y_{i i}=14$. and the efficiency loss is 2.5604 or $18.28 \%$.

It may be interesting to compare our result with the one in Bulow and Levin (2006). Bulow and Levin (2006) analyzed the performance of a centralized matching procedure with a preplay stage of a game of salary determination. They showed that there is only a mixed-strategy equilibrium, and the equilibrium payoffs for firms are higher while the payoffs for applicants are mostly lower under the centralized matching procedure than under the minimum competitive equilibrium salaries. In this example we see

\begin{tabular}{|c|c|c|c|}
\hline Firms & Bulow-Levin's Centralized & Min. Competitive Eq. & Our Game \\
\hline$u_{1}$ & 6.67 & 6.00 & 6.00 \\
\hline$u_{2}$ & 3.67 & 3.00 & 3.00 \\
\hline$u_{3}$ & 1.00 & 1.00 & 1.00 \\
\hline
\end{tabular}

\begin{tabular}{|c|c|c|c|}
\hline Applicants & Bulow-Levin's Centralized & Min. Competitive Eq. & Our Game \\
\hline$v_{1}$ & 1.56 & 3.00 & 1.05 \\
\hline$v_{2}$ & 0.73 & 1.00 & 0.39 \\
\hline$v_{3}$ & 0.02 & 0.00 & 0.00 \\
\hline
\end{tabular}

Thus, applicants' expected payoffs in the centralized matching procedure in Bulow and Levin (2006) are mostly worse than in the minimum competitive equilibrium outcome, but the applicants' equilibrium payoffs in our one-shot offer-acceptance game are even worse than Bulow and Levin's. The sum of expected payoffs of all players in the centralized matching procedure is 13.65, so the efficiency loss is only $2.5 \%$ compared with the $18.28 \%$ loss in our decentralized matching. This is because in the centralized matching procedure, each applicant is matched with at least some firms (although 
there can be mismatches). In contrast, our decentralized matching leaves some applicants unmatched with any hospitals.

Finally, the reader may wonder about pure strategy equilibria. Unfortunately, there can be pathological pure strategy equilibria that achieve a higher salary vector than the minimum competitive salary vector in some cases. Consider the following example.

Example 2. Consider $F=\left\{f_{1}, f_{2}, f_{3}, f_{4}\right\}$ and $A=\left\{a_{1}, a_{2}\right\}$. Suppose that $f_{1}$ and $f_{3}$ make $s_{1}=Y_{11}-\epsilon-Y_{12}+Y_{22}$ offers to $a_{1}$, and $f_{2}$ and $f_{4}$ make $s_{2}=Y_{22}-\epsilon$ offers to $a_{2}$ with probability one ( $\epsilon$ is a small positive number). This is a pure strategy equilibrium, and $s_{1}>s_{1}^{*}$ and $s_{2}>s_{2}^{*}$ hold. ${ }^{14}$ This happens for the following reason. Under this strategy profile, $f_{1}$ and $f_{2}$ are matched with $a_{1}$ and $a_{2}$ and get payoffs $\epsilon+Y_{12}-Y_{22}$ and $\epsilon$, respectively, while $f_{3}$ and $f_{4}$ are unmatched and get zero payoffs. Thus, $f_{3}$ and $f_{4}$ do not lose anything by making unreasonable offers. However, in a pure strategy equilibrium, these unreasonable offers threaten $f_{1}$ and $f_{2}$, and force them to make good offers.

This example is not robust in the sense that it cannot be an equilibrium with weakly dominant strategies. Moreover, obviously, if we assume that making an offer is slightly costly, we can exclude the possibility of a pure strategy equilibrium. We can also claim the following.

Proposition 2. If $n \geq 2, m \geq 2$, and $n<2 m$, then there is no pure strategy equilibrium in a one-shot game. ${ }^{15}$

This proposition says that even if there is no cost to making an unsuccessful offer, there is no pure strategy equilibrium as long as the number of firms is less than twice that of applicants. Otherwise, there is a pure strategy equilibrium, but it is not robust in that the equilibrium involves weakly dominated strategies and does not survive the introduction of low costs to making offers.

\footnotetext{
${ }^{14}$ The inequality $s_{2}>s_{2}^{*}$ is obvious. For the other inequality, note that $s_{1}^{*}=Y_{21}-$ $Y_{22}+Y_{32}$. By strict supermodularity, $Y_{11}-Y_{12}>Y_{21}-Y_{22}$, and by strict increasingness, $Y_{22}>Y_{32}$. Thus, $s_{1}>s_{1}^{*}$ holds, too.

${ }^{15}$ If $m=1$ and/or $n=1$, then there is a pure strategy equilibrium. If $m=1, f_{1}$ gets $a_{1}$ with salary $Y_{21}$ if $n \geq 2$. If $n=1, f_{1}$ gets $a_{1}$ with a zero salary.
} 


\section{Multistage Game}

In this section, we consider a multistage game with a specific structure. The process of making and accepting offers in the real world is very complex, and to simplify it we need to impose many constraints. Moreover, we have to make detailed assumptions in order to specify a noncooperative game. Obviously, the equilibrium of a game depends on the set of assumptions we impose. Our strategy in choosing assumptions is to keep our game as simple as possible.

The game can be described as follows. We assume that each offer is an open offer that is valid until the end of the game. This open offer assumption is not quite realistic, but we still see many possible equilibria even with the open offer restriction.

There is a large finite number of stages $\ell=1,2, \ldots, L$. Each firm $f_{i}$ decides which applicant to make an offer to, at which stage to make the offer, and how much salary to offer her. We assume that an offer is a take-it-or-leaveit offer: each firm $f_{i}$ can make only one offer to $a_{j} .{ }^{16}$ This assumption says that once $f_{i}$ is rejected by $a_{j}$, then $f_{i}$ cannot make any more offers to $a_{j}$. Each firm is allowed to have at most one outstanding offer at a time. This assumption may be viewed as making the cost of multiple applicants for one position prohibitively high. We assume that if no offer is made by any firm in a stage, then the game ends at that stage, and unmatched firms and applicants at that time will not be matched in aftermarket activities. If this assumption is not in place, then the last stage becomes important (in the last stage, a mixed-strategy equilibrium is played which was discussed in the previous section). We also assume that it costs a small amount to make an offer to an applicant. This assumption discourages firms from making irrelevant offers.

Each applicant $a_{j}$ can accept or reject the offers she receives from firms. Once applicant $a_{j}$ accepts an offer from firm $f_{i}$ they are matched and are out of the game: their contract is final and cannot be renegotiated. Recall that each applicant cares only about salaries offered by firms, unless the offered salaries are exactly the same. We retain the same tie-breaking rule introduced in the previous section: if an applicant $a_{j}$ receives offers from $f_{i}$ and $f_{i^{\prime}}$ with the same salaries $\left(i<i^{\prime}\right)$, then $a_{j}$ prefers $f_{i}$ to $f_{i^{\prime}}$. We assume

\footnotetext{
${ }^{16}$ This rule was proposed by Roth and Xing (1994) as an equilibrium refinement. If $f_{i}$ makes an offer and $a_{j}$ rejects it, $f_{i}$ cannot go back to $a_{j}$ making an offer with a higher salary. That is, there is no room for salary negotiation.
} 
that if an applicant receives multiple offers, she will reject all offers but one immediately (i.e., will keep or accept only the most preferable one). This assumption is made in order to avoid unnecessary delays in the process.

We focus on a restrictive set of stationary Markov strategies, since there is a lot of freedom even with the above constraints. We first need to introduce a concept: A state is a list of applicants who have not accepted an offer (active applicants), firms whose offers have not been accepted (active firms), pending offers among active players (where each pending offer is a list of a firm, an applicant, and a salary), and rejected offers among active players (each rejected offer is a list of a firm and an applicant: the proposed salary is assumed to be irrelevant for a rejected one). A stationary Markov strategy is a strategy for a player that maps a state to an action. That is, each firm cares only about information such as who is available to it with what conditions (a pending salary), and which firms are its potential competitors. Without stationarity, making an irrelevant offer (an offer that would not be accepted in any case) may bring about a totally different equilibrium in a subgame, which can affect the equilibrium outcome. A subgame perfect equilibrium with stationary Markov strategies is called a stationary Markov perfect equilibrium.

Formally, states are defined in the following manner: in stage $\ell$, let $F^{\prime} \subseteq F$ and $A^{\prime} \subseteq A$ be active firms and applicants of the game, that is, players who have not exited the game by finalizing contracts. That is, $F \backslash F^{\prime}$ and $A \backslash A^{\prime}$ have already been matched up, and $F^{\prime}$ and $A^{\prime}$ are the only active players, and there is no rejected offer or pending offer among $F^{\prime}$ and $A^{\prime}$. With rejected offers and states with pending offers, a state is described as a list $\left(F^{\prime}, A^{\prime} ; R ; P\right)$, where $R=\left\{(f, a) \in F^{\prime} \times A^{\prime}: a\right.$ has rejected an offer from $f\}$ and $P=\left\{\langle f, a, s\rangle \in F^{\prime} \times A^{\prime} \times \mathbb{R}_{+}: a\right.$ has not accepted an offer from $f$ with salary $s\}$. Obviously, for any $\langle f, a, s\rangle \in P,(f, a) \notin R$ holds. Let $F_{P}^{\prime}=\left\{f \in F^{\prime}: \exists\langle f, a, s\rangle \in P\right\}$ and $A_{P}^{\prime}=\left\{a \in A^{\prime}: \exists\langle f, a, s\rangle \in P\right\}$. We need a little more notation. Let $f_{i}\left(F^{\prime}\right)$ be the $i$ th best firm among $F^{\prime}$ $\left(i=1, \ldots,\left|F^{\prime}\right|\right)$, and let $a_{j}\left(A^{\prime}\right)$ be the $j$ th best firm among $A^{\prime}\left(j=1, \ldots,\left|A^{\prime}\right|\right)$. A matrix $\left.Y\right|_{F^{\prime}, A^{\prime}}$ is a restriction of production matrix $Y$.

Our first result is that the minimum competitive salary vector $\mathbf{s}^{*}$ can be an outcome of a stationary Markov perfect equilibrium. We will support the following equilibrium path:

in stage $\ell=1,2, \ldots, \min \{n, m\}, f_{\ell}$ makes an offer to $a_{\ell}$ with salary $s_{\ell}^{*}$, and $a_{\ell}$ immediately accepts it. At the end of stage $\min \{n, m\}$, 
the game ends.

Thus, after $\min \{n, m\}$ stages, all matchings are made and the assortative matching is realized with the minimum competitive salary profile. Now, we will show that this path can be supported as a subgame perfect equilibrium. We have the following proposition.

Proposition 3. In a multistage game, there is a stationary Markov perfect equilibrium path such that in stage $\ell=1, \ldots, \min \{n, m\}, f_{\ell}$ makes an offer with $s_{\ell}^{*}$ to $a_{\ell}$ and $a_{\ell}$ accepts the offer immediately. Thus, the resulting payoff vector for firms is $\mathbf{u}^{*}=\left(u_{1}, \ldots, u_{n}\right)$, where $u_{i}^{*}=Y_{i i}-s_{i}^{*}$ for all $i \leq \min \{n, m\}$ and $u_{i}^{*}=0$ if $n>m$.

To show this, we need to specify a stationary Markov perfect equilibrium strategy profile which generates the path described above. Since it is lengthy and cumbersome, the formal description of strategy profile is provided in an appendix. The basic idea is as follows: in each stage the best remaining applicant obtains an offer from the best firm that can make an offer to her (the firm has not been rejected by her, and has no pending offer). If the offered salary is more than or equal to the minimum competitive salary given the constraints of existing rejected and pending offers, then she accepts the offer. Otherwise, she waits for a better offer. In the latter case, some other firm has an incentive to counter the original offer, and the original offer will be rejected. As a result, the best firm eventually receives a lower payoff than it would by making a minimum competitive salary offer to the best applicant, since only the second-best applicant is available after the firm is rejected by the best applicant. Thus, under such a strategy profile, the best (available) firm should offer exactly the minimum competitive salary to the best available applicant, and they will be matched up.

Although Proposition 3 says that $\mathbf{s}^{*}$ is supportable, there are many more stationary Markov perfect equilibria. To illustrate, we provide two examples.

Example 3. Consider the case where $m=n=2$.

$$
Y=\left(\begin{array}{ll}
Y_{11} & Y_{12} \\
Y_{21} & Y_{22}
\end{array}\right)
$$

Consider the following strategy profile. In stage $1, f_{2}$ makes a zero salary offer to $a_{2}$, and in stage $2, f_{1}$ makes a zero salary offer to $a_{1}$. Offers are accepted immediately. This is a stationary Markov perfect equilibrium. As 
long as an offer is made in stage 1 by $f_{2}$, then the game continues, and $f_{2}$ can make an offer to $a_{1}$. However, $f_{2}$ cannot get $a_{1}$ since $f_{1}$ would match the offer and needs to pay an additional cost of making an irrelevant offer.

Salary vector $\mathbf{s}=(0,0)$ is not a competitive equilibrium price vector, and thus it is not in the core. However, in the subgame $\left(F^{\prime}, A^{\prime}\right)=\left(\left\{f_{1}\right\},\left\{a_{1}\right\}\right)$, $s_{1}=0$ is a competitive equilibrium price, and so is in the core. Although transfers are not allowed, the structure of the above example is similar to Example 3.1 in Bloch and Diamantoudi (2006), which shows that there is a noncore allocation that is supported by a stationary Markov perfect equilibrium in a sequential move game of a marriage problem. ${ }^{17}$ Note that such an equilibrium is very robust. For any game with $n \leq m$, there is a zero-salary equilibrium. If $n>m$, then $\mathbf{s}^{\prime}=\left(Y_{m+1,1}, Y_{m+1,2}, \ldots Y_{m+1, m}\right)$ is an outcome of a stationary Markov perfect equilibrium $\left(f_{m}\right.$ makes a $s_{m}^{\prime}=Y_{m+1, m}$ offer to $a_{m}$ in stage 1 , since $f_{m+1}$ can counter; otherwise: the rest is the same).

Unfortunately, this stationary restriction on strategy space is not sufficiently powerful to exclude unintuitive equilibria. A firm can make a useless offer to an applicant only to be rejected by her, which changes the current state. Since firms' strategies depend on the states they are in, the equilibrium outcome can be affected by such a seemingly irrelevant state switch initiated by the firm. Thus, with multiple equilibria in subgames, we can still cook up variety of equilibrium outcomes.

Example 4. Consider the case where $m=n=3$.

$$
Y=\left(\begin{array}{lll}
Y_{11} & Y_{12} & Y_{13} \\
Y_{21} & Y_{22} & Y_{23} \\
Y_{31} & Y_{32} & Y_{33}
\end{array}\right)
$$

We can cook up a stationary Markov perfect equilibrium strategy profile. First $f_{1}$ and $f_{2}$ make offers to $a_{1}$ with the same salaries $\delta \in\left(s_{1}^{*}, Y_{11}-Y_{12}\right)$, and $a_{1}$ rejects $f_{2}$ but does not immediately accept $f_{1}$. This delay in acceptance makes a difference. ${ }^{18}$ Let us assume that only in state $\left(F, A ;\left(f_{2}, a_{1}\right) ;\left\langle f_{1}, a_{1}, \delta\right\rangle\right)$,

\footnotetext{
${ }^{17}$ The sequential move game employed by Bloch and Diamantoudi (2006) is the standard one in coalitional bargaining literature (Chatterjee, Dutta, Ray and Sengupta, 1993, Bloch, 1996, Okada, 1996, and Ray and Vohra, 1999), which is very different from ours.

${ }^{18}$ If $f_{1}$ 's offer were accepted immediately, then the state is described only by $A^{\prime}=$ $\left\{a_{2}, a_{3}\right\}$ and $F^{\prime}=\left\{f_{2}, f_{3}\right\}$. Thus, $f_{2}$ 's action cannot affect the outcome with Markov strategies. It might look irrelevant if $a_{1}$ holds $f_{1}$ 's offer for one period (and obviously
} 
$f_{3}$ moves first to make a zero salary offer to $a_{3}$, and $a_{1}$ and $a_{3}$ accept the offers. At the same time, in states $\left(F, A ; \emptyset ;\left\langle f_{1}, a_{1}, \delta\right\rangle\right)$ and $\left(\left\{f_{2}, f_{3}\right\},\left\{a_{2}, a_{3}\right\} ; \emptyset ; \emptyset\right)$, $f_{2}$ makes an $s_{2}^{*}$ offer to $a_{2}$, and $a_{2}$ (and $a_{1}$ if $a_{1}$ is still there) accepts the offer. The leftover firm offers a zero salary to the leftover applicant. This is a stationary Markov perfect equilibrium, and the equilibrium path is as follows: in stage $1 f_{1}$ and $f_{2}$ make a $\delta$ offer to $a_{1}$ with salary $\delta$, and $f_{2}$ is rejected ( $f_{1}$ 's offer is pending). In stage $2, f_{3}$ makes a zero salary offer to $a_{3}$, and $a_{1}$ and $a_{3}$ accept the offers. In stage $3, f_{2}$ makes a zero salary offer to $a_{2}$, and $a_{2}$ accepts it. Although $f_{2}$ needs to pay for the offer to be rejected, as long as the cost is less than $s_{2}^{*}, f_{2}$ is better off making an offer to $a_{1}$, since otherwise, at the next stage $f_{2}$ will need to make a $s_{2}^{*}$ offer to $a_{2}$, and the payoff is just $Y_{22}-s_{2}^{*}$. By making an irrelevant offer, in the next stage, $f_{3}$ moves first, and $f_{2}$ can get $a_{2}$ with a zero salary. If $f_{1}$ does not make an offer in stage $1, f_{2}$ gets $a_{1}$, and $f_{1}$ can get at most $Y_{12}$ (with zero salary for $\left.a_{2}\right)$. Thus, $f_{1}$ has an incentive to make an offer $\delta \leq Y_{11}-Y_{12}$ to $a_{2}$. That is, depending on $f_{2}$ 's seemingly irrelevant choice in stage 1 , the real outcome can be affected by having a rejection on the equilibrium path.

Although the equilibrium in Example 4 is robust (it is not an equilibrium with weakly dominated strategies, and survives with small costs of making offers) ${ }^{19}$ the nature of the equilibrium is still somewhat pathological. Firm $f_{1}$ makes a very high salary offer to $a_{1}$ due to $f_{2}$ 's threat. However, $f_{2}$ 's motivation to make an offer to $a_{1}$ is only to be rejected and effect a change in the following subgames. With a cost attached to making offers, a rejection on the equilibrium path can occur only under such a situation. Thus, we next consider a stationary Markov equilibrium without rejections on the equilibrium path.

Proposition 4. Suppose $n \geq 2$ and $m \geq 2$. In a multistage game, in any pure strategy stationary Markov perfect equilibrium without any rejections on the equilibrium path, the equilibrium salary vector satisfies $\mathbf{s} \leq \mathbf{s}^{*}$, and the firms' payoff vector satisfies $\mathbf{u} \geq \mathbf{u}^{*}$, where $u_{i}^{*}=Y_{i i}-s_{i}^{*}$ for all $f_{i} \in F$.

holding an offer is not a weakly dominated strategy), but it makes a big difference in this (artificial) example.

${ }^{19}$ In our game, avoiding complexity of strategies does not do much either: i.e., lexicographic minimization of complexity costs à la Gale and Sabourian (2006) does not refine our stationary Markov equilibrium. We thank Jihong Lee for clarifying this point to us. 
This proposition says that if there is no rejection on the equilibrium path, then the equilibrium salary vector is not more than the minimum competitive salary vector. We conclude this section by providing an example in which the assortative matching is not necessarily the only equilibrium outcome. That is, there can be an inefficient equilibrium.

Example 5. Consider the case where $m=n=4$ with the following multiplicative output matrix.

$$
Y=\left(\begin{array}{cccc}
16 & 12 & 8 & 4 \\
12 & 9 & 6 & 3 \\
8 & 6 & 4 & 2 \\
4 & 3 & 2 & 1
\end{array}\right)
$$

Consider the following path: First, firm $f_{1}$ makes an offer to $a_{2}$ with $s_{2}=2$. Then, firm $f_{4}$ makes a zero salary offer to $a_{4}$. Then, firm $f_{3}$ makes a zero salary offer to $a_{3}$. Finally, firm $f_{2}$ makes a zero salary offer to $a_{1}$. All offers are accepted by the end of the game. With these actions, the firms' payoff vector is $\mathbf{u}=(10,12,4,1)$. To make $f_{1}$ not deviate in making an offer to $a_{1}$, we can prepare the following perfect equilibrium in the subgame: If $f_{1}$ offers $s_{1}<6$, then $f_{2}$ makes a counteroffer to $a_{1}$ with $s_{1}^{\prime}=\max \left\{s_{1}+\epsilon, 5\right\}$, and otherwise, $f_{2}$ makes an offer to $a_{2}$ with $s_{2}=3$. Then, $f_{3}$ and $f_{4}$ follow sequentially by making offers to $a_{3}$ and $a_{4}$ with $s_{3}=1$ and $s_{4}=0$, respectively. This subsequent path corresponds to the highest salary equilibrium, and $f_{1}$ needs to pay $s_{1}=6$ in order to get $a_{1}$ (the resulting payoff vector is $\left.\mathbf{u}^{*}=(10,6,3,1)\right)$. Thus, $f_{1}$ is indifferent between deviating and not deviating. ${ }^{20}$ Firm $f_{2}$ has no incentive to deviate, since the equilibrium outcome is the best-case scenario for it. Firm $f_{3}$ has no incentive to make a counteroffer to $a_{2}$, since it needs to pay $s_{2}^{\prime}>s_{2}=2$ (the payoff by deviating is less than 4). The same remark applies to $f_{4}$. Thus, the above path is supportable as an equilibrium path.

\section{Conclusion}

Bulow and Levin (2006) asserted that salaries are more suppressed under the centrally planned matching mechanism than under a decentralized mar-

\footnotetext{
${ }^{20}$ We can modify the example by reducing $Y_{11}$ slightly from 16 without damaging strict supermodularity and strict monotonicity, if we want to give $f_{1}$ a strict incentive to follow the equilibrium path.
} 
ket. However, they used the minimum competitive salary vector (a Vickrey auction salary vector) as the outcome of the decentralized market. In the real labor market, a decentralized market will involve a collection of bilateral offers and applicants' accept/reject decisions. In this paper, we have compared the equilibrium salary vectors in such situations by specifying games in tractable manners. We have shown three results. First, under a simultaneous move game, in any mixed-strategy equilibria, the resulting (expected) salary vector is dominated by the minimum competitive salary vector (Proposition 1). Second, under a sequential move game with open offers, there is a stationary Markov perfect equilibrium that attains the minimum competitive salaries (Proposition 3). If rejections are not allowed on the equilibrium path, any stationary Markov perfect equilibrium attains at most the minimum competitive salaries (Proposition 4). We also demonstrated that there are many other stationary Markov perfect equilibria (Examples 3 and 4).

Our games are admittedly too simplistic in comparison with real-world market institutions. In a simultaneous move game, one of the most problematic issues is that we do not allow after-market job matchings among firms and applicants who could not be matched in the market. However, it is very hard to formalize the concept of an "after market" since it is not clear how it differs from a decentralized bilateral labor market.

In multistage game, the main problem is our "open offer" assumption: an offer is good for a long period until it has been accepted or rejected by the applicant. Real-world offers usually have deadlines, sometimes very short (exploding offers). To evaluate the performance of NRMP in comparison with the decentralized market, ideally we should use equilibrium salary vectors of the games that mimic the real-world market institutions as reference salary vectors of decentralized matching markets. However, exploding offers are very difficult to analyze especially if they involve endogenized salaries. ${ }^{21} \mathrm{We}$ hope to extend our analysis by adopting more realistic assumptions in our future research.

\footnotetext{
${ }^{21}$ One simple way to introduce exploding offers is to adopt a framework of sequential bargaining or coalition bargaining game (see Chatterjee et al. 1993, Bloch 1996, Okada 1996, and Ray and Vohra 1999). In each stage, one firm is selected as a proposer (randomly or in some order), and it can make an offer to an applicant. However, in such a setting (only firms can make offers) with exploding offers, the resulting salaries are zeros or very close to zeros. This is why we adopt the framework provided by Roth and Xing (1994).
} 


\section{Proofs}

We collect all the proofs of the lemma and propositions in the main text.

Lemma 1. If the output matrix $Y$ is strictly supermodular and strictly increasing then the minimum competitive salary vector is $\mathbf{s}^{*}=\left(s_{1}^{*}, \ldots, s_{m}^{*}\right)$ where (i) $s_{j}^{*}=\sum_{j^{\prime}=j}^{n-1}\left(Y_{j^{\prime}+1 j^{\prime}}-Y_{j^{\prime}+1 j^{\prime}+1}\right)$ for any $j \leq n-1$ and $s_{j}^{*}=0$ for $j \geq n$ when $n \leq m$, and (ii) $s_{j}^{*}=Y_{m m}+\sum_{j^{\prime}=j}^{m-1}\left(Y_{j^{\prime}+1 j^{\prime}}-Y_{j^{\prime}+1 j^{\prime}+1}\right)$ for any $j \leq m-1$ and $s_{m}^{*}=Y_{m+1 m}$ when $n>m$.

Proof : Shapley and Shubik (1972) showed that if an outcome of an assignment problem is stable then the assignment matrix associated with it is an optimal assignment. Under strict supermodularity and strict increasingness, the unique optimal assignment of the output matrix $Y$ is an assortative matrix $X^{*}$. Thus, what is left to show is that the minimum salary vector that supports this assignment is $\mathbf{s}^{*}$ where $(\mathrm{i}) s_{j}^{*}=\sum_{j^{\prime}=j^{\prime}}^{n-1}\left(Y_{j^{\prime}+1 j^{\prime}}-Y_{j^{\prime}+1 j^{\prime}+1}\right)$ for any $j \leq n-1$ and $s_{j}^{*}=0$ for any $j \geq n$ when $m \geq n$, and (ii) $s_{j}^{*}=Y_{m+1 m}+\sum_{j^{\prime}=j}^{m-1}\left(Y_{j^{\prime}+1 j^{\prime}}-Y_{j^{\prime}+1 j^{\prime}+1}\right)$ for any $j \leq m-1$ and $s_{m}^{*}=Y_{m+1 m}$ when $n>m$.

Suppose not. Then there is a competitive salary vector $\mathbf{s}^{\prime}$ with $s_{j}^{\prime}<s_{j}^{*}$ for some $j$. First assume $n \leq m$. Obviously, such $j$ must belong to $\{1, \ldots n-1\}$, suppose that $s_{n-1}^{\prime}<s_{n-1}^{*}$, and thus $s_{n-1}^{\prime}<Y_{n n-1}-Y_{n n}$. Consider a deviation by a pair $\left(f_{n}, a_{n-1}\right)$. Since $s_{n}^{\prime} \geq s_{n}^{*}=0, \pi_{n}^{\prime} \leq Y_{n n}$. Now, $s_{n-1}^{\prime}+\pi_{n}^{\prime}<$ $Y_{n n-1}-Y_{n n}+Y_{n n}=Y_{n n-1}$. This violates stability, and contradicts $\mathbf{s}^{\prime}$ being a competitive salary. Thus $s_{n-1}^{\prime} \geq s_{n-1}^{*}$. Suppose that $s_{n-2}^{\prime}<s_{n-2}^{*}$, and thus $s_{n-2}^{\prime}<Y_{n-1 n-2}-\left(Y_{n-1 n-1}-\left(Y_{n n-1}-Y_{n n}\right)\right)$. From the previous step, we know $s_{n-1}^{\prime} \geq s_{n-1}^{*}$, and thus $\pi_{n-1}^{\prime} \leq Y_{n-1 n-1}-s_{n-1}^{*}=Y_{n-1 n-1}-\left(Y_{n n-1}-Y_{n n}\right)$. Thus, we have

$$
\begin{aligned}
s_{n-2}^{\prime}+\pi_{n-1}^{\prime} & <Y_{n-1 n-2}-\left(Y_{n-1 n-1}-\left(Y_{n n-1}-Y_{n n}\right)\right)+Y_{n-1 n-1}-\left(Y_{n n-1}-Y_{n n}\right) \\
& =Y_{n-1 n-2} .
\end{aligned}
$$

This violates stability, and contradicts $\mathbf{s}^{\prime}$ being a competitive salary. Thus $s_{n-2}^{\prime} \geq s_{n-2}^{*}$. Repeated applications of the same logic yield that any competitive salary vector $\mathbf{s}^{\prime}$ satisfies $\mathbf{s}^{\prime} \geq \mathbf{s}^{*}$.

Second, assume $n>m$. Then obviously such $j$ with $s_{j}^{\prime}<s_{j}^{*}$ must satisfy $j \leq m$. Suppose $s_{m}^{\prime}<s_{m}^{*}=Y_{m+1 m}$. Then, a deviation by a pair $\left(f_{m+1}, a_{m}\right)$ can block the allocation, since in the allocation $\pi_{m+1}=0$ and $s_{m}^{\prime}<Y_{m+1 m}$. This is a contradiction. Thus $s_{m}^{\prime} \geq s_{m}^{*}$. Since in the allocation firm $f_{m}$ 
gets $\pi_{m}=Y_{m m}-s_{m}^{\prime} \leq Y_{m m}-s_{m}^{*}=0$, we conclude $s_{m}^{\prime}=s_{m}^{*}$. Now suppose $s_{m-1}^{\prime}<s_{m-1}^{*}$. In this case, a deviation by a pair $\left(f_{m}, a_{m-1}\right)$ can improve upon the allocation since $\pi_{m}=0$ and $s_{m-1}^{\prime}<Y_{m m}+\left(Y_{m m-1}-Y_{m m}\right)=Y_{m m-1}$. This is a contradiction, and we conclude $s_{m-1}^{\prime} \geq s_{m-1}^{*}$. Now suppose that $s_{m-2}^{\prime}<s_{m-2}^{*}$, thus $s_{m-2}^{\prime}<Y_{m-1 m-2}-Y_{m-1 m-1}+Y_{m m-1}$. From the previous step, we know $s_{m-1}^{\prime} \geq s_{m-1}^{*}=Y_{m m-1}$, and thus $\pi_{m-1}^{\prime} \leq Y_{m-1 m-1}-s_{m-1}^{*}=$ $Y_{m-1 m-1}-Y_{m m-1}$. Thus, we have

$$
\begin{aligned}
s_{m-2}^{\prime}+\pi_{m-1}^{\prime} & <Y_{m-1 m-2}-Y_{m-1 m-1}+Y_{m m-1}+Y_{m-1 m-1}-Y_{m m-1} \\
& =Y_{m-1 m-2} .
\end{aligned}
$$

This violates stability, and contradicts $\mathbf{s}^{\prime}$ being a competitive salary. Thus $s_{m-2}^{\prime} \geq s_{m-2}^{*}$. Repeated applications of the same logic show that any competitive salary vector $\mathbf{s}^{\prime}$ satisfies $\mathbf{s}^{\prime} \geq \mathbf{s}^{*}$.

Proposition 1. Suppose that $Y$ is strictly supermodular and strictly increasing, and that $n \geq 2$ and $m \geq 2$. In any mixed-strategy equilibrium $G$ in a one-shot game, we have: for all $i=1, \ldots, n$ and all $j=1, \ldots, m$, (i) $\bar{s}_{j}=s_{j}^{*}$ for all $j=1, \ldots, m$, (ii) $u_{i}(G)=Y_{i i}-s_{i}^{*}$ for all $i \leq \min \{n, m\}$ and $u_{i}(G)=0$ if $n>m$, and (iii) $v_{j}(G)<s_{j}^{*}$ for all $j \leq \min \{n-1, m\}$ and $v_{j}(G)=s_{j}^{*}=0$ for all $j>\min \{n-1, m\}$.

We will prove Proposition 1 by a sequence of claims.

Claim 1. (No spikes) For all $a_{j}$, no firm $f_{i}$ plays $\left(a_{j}, s\right)$ for any $s \in\left(0, \bar{s}_{j}\right]$ with a positive probability when $\bar{s}_{j}>0$.

Proof. Suppose that a firm $f_{i}$ makes an offer of salary $s>0$ to $a_{j}$ with a positive probability. Then for all other firms, the winning probability function $w_{i^{\prime} j}$ jumps down at $s$. Thus, no other firm plays $\left(a_{j}, s^{\prime}\right)$ with positive density for $s^{\prime}=s-\epsilon$ for $\epsilon>0$ small enough. This gives $f_{i}$ an incentive to shift the spike at $s$ slightly lower. Thus, in equilibrium, $f_{i}$ would not play $\left(a_{j}, s\right)$ with a positive probability for any $s \in\left(0, \bar{s}_{j}\right]$

Claim 2. (No gap for at least a pair of firms) For all $a_{j}$, and all intervals $\left(s_{j}^{\prime}, s_{j}^{\prime \prime}\right) \subset\left(0, \bar{s}_{j}\right)$, there are at least two firms with $G_{i j}\left(s_{j}^{\prime}\right)<G_{i j}\left(s_{j}^{\prime \prime}\right)$.

Proof. First note that there is a firm $f_{i}$ such that $G_{i j}\left(\bar{s}_{j}-\epsilon\right)<G_{i j}\left(\bar{s}_{j}\right)$ holds for all $\epsilon>0$. Firm $f_{i}$ obtains its expected payoff of $Y_{i j}-\bar{s}_{j}$ by this offer since 
$w_{i j}\left(\bar{s}_{j}\right)=1$. Thus, there is another firm that plays $\left(a_{j}, s\right)$ for some $s \in\left(s_{j}^{\prime \prime}, \bar{s}_{j}\right]$. Note that $s_{j}^{\prime \prime}<\bar{s}_{j}$ (by the definition of $\bar{s}_{j}$ ). Without loss of generality, we can let $G_{i^{\prime} j}\left(s_{j}^{\prime \prime}+\epsilon\right)-G_{i^{\prime} j}\left(s_{j}^{\prime \prime}\right)>0$ for all $\epsilon>0$ for some $f_{i^{\prime}}$. Focus on this firm. Suppose that there is no firm that offers any of $s_{j} \in\left(s_{j}^{\prime}, s_{j}^{\prime \prime}\right)$ to $a_{j}$. Then, $w_{i^{\prime} j}\left(s_{j}^{\prime}\right)=w_{i^{\prime} j}\left(s_{j}^{\prime \prime}\right)$, and firm $i^{\prime}$ would be better off making an $s_{j}^{\prime}$ offer to $a_{j}$, which is a contradiction. Thus, there is at least one such firm. Moreover, if firm $f_{i^{\prime}}$ is the only such a firm, then again $w_{i^{\prime} j}\left(s_{j}^{\prime}\right)=w_{i^{\prime} j}\left(s_{j}^{\prime \prime}\right)$ follows. This is again a contradiction, and we have shown that at least two firms make salary offers within the interval $\left(s_{j}^{\prime}, s_{j}^{\prime \prime}\right)$ to $a_{j}$ with positive probabilities.

Note that

$$
\begin{aligned}
w_{i j}\left(s_{j}\right) & =\prod_{i^{\prime} \neq i}\left(1-\left(G_{i^{\prime} j}\left(\bar{s}_{j}\right)-G_{i^{\prime} j}\left(s_{j}\right)\right)\right) \\
& =\frac{\prod_{i^{\prime}=1}^{r}\left(1-\left(G_{i^{\prime} j}\left(\bar{s}_{j}\right)-G_{i^{\prime} j}\left(s_{j}\right)\right)\right)}{\left(1-\left(G_{i j}\left(\bar{s}_{j}\right)-G_{i j}\left(s_{j}\right)\right)\right)}
\end{aligned}
$$

This implies

$$
w_{i j}\left(s_{j}\right) \gtreqless w_{i^{\prime} j}\left(s_{j}\right) \Leftrightarrow G_{i j}\left(\bar{s}_{j}\right)-G_{i j}\left(s_{j}\right) \gtreqless G_{i^{\prime} j}\left(\bar{s}_{j}\right)-G_{i^{\prime} j}\left(s_{j}\right) .
$$

Thus, we have the following:

Claim 3. For all $i, i^{\prime}=1, \ldots, n$ and all $j=1, \ldots, m, 0<\bar{s}_{i j}<\bar{s}_{i^{\prime} j}=\bar{s}_{j}$ implies $i^{\prime}<i$.

Proof. By definition, we have $w_{i j}\left(\bar{s}_{i j}\right)\left(Y_{i j}-\bar{s}_{i j}\right)=u_{i}(G) \geq Y_{i j}-\bar{s}_{j}$. Thus, we have

$$
w_{i j}\left(\bar{s}_{i j}\right) \geq \frac{Y_{i j}-\bar{s}_{j}}{Y_{i j}-\bar{s}_{i j}} .
$$

Similarly, since $\bar{s}_{i^{\prime} j}=\bar{s}_{j}$, we have $w_{i^{\prime} j}\left(\bar{s}_{i j}\right)\left(Y_{i^{\prime} j}-\bar{s}_{i j}\right) \leq Y_{i^{\prime} j}-\bar{s}_{j}=u_{i^{\prime}}(G)$. This implies

$$
w_{i^{\prime} j}\left(\bar{s}_{i j}\right) \leq \frac{Y_{i^{\prime} j}-\bar{s}_{j}}{Y_{i^{\prime} j}-\bar{s}_{i j}} .
$$

Since $G_{i^{\prime} j}\left(\bar{s}_{i j}\right)<G_{i^{\prime} j}\left(\bar{s}_{j}\right)$ (from $\bar{s}_{i^{\prime} j}=\bar{s}_{j}$ ) and $G_{i j}\left(\bar{s}_{i j}\right)=G_{i j}\left(\bar{s}_{j}\right)$, (1) implies $w_{i j}\left(\bar{s}_{i j}\right)<w_{i^{\prime} j}\left(\bar{s}_{i j}\right)$. Thus, we have

$$
\frac{Y_{i j}-\bar{s}_{j}}{Y_{i j}-\bar{s}_{i j}}<\frac{Y_{i^{\prime} j}-\bar{s}_{j}}{Y_{i^{\prime} j}-\bar{s}_{i j}}
$$

or $Y_{i j}<Y_{i^{\prime} j}$. This completes the proof. 
Claim 4. For any $j=1, \ldots, n-1$, we have (i) $\bar{s}_{j}=\bar{s}_{j j}=\bar{s}_{j+1 j}$ and (ii) $\bar{s}_{k j}<\bar{s}_{j}$ for $k \neq j, j+1$.

Proof. By induction. Let $j=1$. Then, by Claim 1, at least two firms make the highest salary offers to $a_{1}$. By Claim $3, f_{1}$ and $f_{2}$ must satisfy $\bar{s}_{11}=\bar{s}_{21}=\bar{s}_{1}$.

Suppose to the contrary that $f_{3}$ also satisfies the same condition: $\bar{s}_{31}=\bar{s}_{1}$. These imply

$$
\begin{aligned}
& Y_{11}-\bar{s}_{1} \geq Y_{1 j}-\bar{s}_{j} \\
& Y_{21}-\bar{s}_{1} \geq Y_{2 j}-\bar{s}_{j} \\
& Y_{31}-\bar{s}_{1} \geq Y_{3 j}-\bar{s}_{j}
\end{aligned}
$$

for all $j=2, \ldots, m$. However, by strict supermodularity, $Y_{\hat{\imath} \hat{\jmath}}-Y_{\hat{\imath} \hat{j}}>Y_{\hat{\imath} \hat{\jmath}}-Y_{\tilde{i} \tilde{j}}$ for all $\hat{\imath}<\tilde{\imath}$ and all $\hat{\jmath}<\tilde{j}$. This implies that the first two inequalities need to be strict, i.e.:

$$
\begin{aligned}
& Y_{11}-\bar{s}_{1}>Y_{1 j}-\bar{s}_{j} \\
& Y_{21}-\bar{s}_{1}>Y_{2 j}-\bar{s}_{j} \\
& Y_{31}-\bar{s}_{1} \geq Y_{3 j}-\bar{s}_{j}
\end{aligned}
$$

for all $j=2, \ldots, m$. By the above inequalities, firms $f_{1}$ and $f_{2}$ must make offers only to $a_{1}$. (If $f_{2}$ makes an offer to $a_{j} \neq a_{1}$, then $\bar{s}_{2 j}<\bar{s}_{j}$ must be satisfied in order to achieve indifference, since $w_{21}\left(\bar{s}_{1}\right)=1$. By Claim 3, this implies $\bar{s}_{1 j}=\bar{s}_{1}$, which is a contradiction.) However, if it were the case, then there is no mixed-strategy equilibrium. (By Claim 1 and our tie-breaking rule, there is no spike in the distribution of $G_{21}$ even at $s_{2}=0$. This implies that $w_{11}\left(\underline{s}_{21}\right)=0$. But then, $G_{11}\left(\underline{s}_{21}\right)=0$. But then, $w_{21}\left(\underline{s}_{21}\right)=0$ as well, and we have $u_{2}(G)=0$, which cannot happen since there are other applicants.) This is a contradiction. Thus, we conclude that only $f_{1}$ and $f_{2}$ make offers to $a_{1}$ with the highest salary $\bar{s}_{1}$. Hence, we have

$$
\begin{aligned}
& Y_{11}-\bar{s}_{1}>Y_{1 j}-\bar{s}_{j} \\
& Y_{21}-\bar{s}_{1} \geq Y_{2 j}-\bar{s}_{j}
\end{aligned}
$$

for all $j=2, \ldots, m$. By supermodularity, an equality holds in the second inequality only when $j=2$.

Now, we move on to $a_{2}$. We focus on the behavior of $f_{2}$. In order to see it, we need to consider $f_{1}$ 's strategy closely. Suppose that $G_{11}(0)=0$. Then, 
by Claim $1, G_{11}$ has no spikes. Given this, for any $\underline{s}_{21} \in\left[0, \bar{s}_{1}\right], w_{11}\left(\underline{s}_{21}\right)=0$ and $G_{11}\left(\underline{s}_{21}\right)=0$. But then, $w_{21}\left(\underline{s}_{21}\right)=0$ as well, and we get $u_{2}(G)=0$. This cannot happen, so we have $w_{11}(0)>0$ and $G_{21}\left(\bar{s}_{1}\right)<1$ (otherwise, $f_{1}$ cannot obtain a positive payoff by making a zero salary offer). This shows that firm $f_{2}$ makes some salary offers to $a_{2}$ with a positive probability, and the maximum offer must be $\bar{s}_{2}$ by Claim 3 again. By the same argument above, firms $f_{2}$ and $f_{3}$ make offers to $a_{2}$ with $\bar{s}_{2}$. The fact that $f_{2}$ 's makes an offer to $a_{1}$ gives $f_{3}$ a positive chance of winning by making a zero salary offer to $a_{2}$.

By repeating the same argument, we complete the proof of this Claim.

Now, we can complete the proof of Proposition 1.

Proof of Proposition 1. We start with the case $n \leq m$. By Claim 4, we know $a_{n}$ gets an offer only from $f_{n}$ with a positive probability. This means that $\bar{s}_{j}=0=s_{j}^{*}$ for all $j \geq n$. Since firm $f_{j+1}$ is indifferent between making an offer to $a_{j}$ with salary $\bar{s}_{j}$ and making an offer to $a_{j+1}$ with a salary $\bar{s}_{j+1}$, in either case the winning probability is $1\left(w_{j+1 j}\left(\bar{s}_{j}\right)=w_{j+1 j+1}\left(\bar{s}_{j+1}\right)=1\right)$. Thus, $Y_{j+1 j}-\bar{s}_{j}=Y_{j+1 j+1}-\bar{s}_{j}$ for all $j=1, \ldots, n-1$. By Claim 1 , we conclude $\bar{s}=s^{*}$. Thus, applicants' payoffs are lower since firms play mixed strategies, and the best-case scenario for each applicant is to get the same salary as the one under the minimum competitive price.

Now consider the case $n>m$. By Claim 4 , we know $a_{m}$ gets offers only from firms $i=m, \ldots, n$. We claim that $\bar{s}_{m}=s_{m}^{*}$ holds and $f_{m+1}$ offers to $a_{m}$ a salary $Y_{m+1 m}$ with probability one. Suppose that $0<\bar{s}_{m}<s_{m}^{*}=Y_{m+1 m}$. Since $f_{m+1}$ obtains a positive expected payoff, the equilibrium must be in mixed strategies. Thus we have

$$
\begin{aligned}
Y_{m+1 m}-\bar{s}_{m} & =w_{m+1 m}\left(s_{m}^{\prime}\right)\left(Y_{m+1 m}-s_{m}^{\prime}\right) \\
Y_{m m}-\bar{s}_{m} & =w_{m m}\left(s_{m}^{\prime}\right)\left(Y_{m m}-s_{m}^{\prime}\right) .
\end{aligned}
$$

Since $Y_{m m}>Y_{m+1 m}$, we have

$$
w_{m m}\left(s_{m}^{\prime}\right)=\frac{Y_{m m}-\bar{s}_{m}}{Y_{m m}-s_{m}^{\prime}}>\frac{Y_{m+1 m}-\bar{s}_{m}}{Y_{m+1 m}-s_{m}^{\prime}}=w_{m+1 m}\left(s_{m}^{\prime}\right) .
$$

For the outcome to be in equilibrium, we need $w_{m m}\left(\underline{s}_{m m}\right)>0$. Suppose that $\underline{s}_{m m}=0$. Since $G_{m m}\left(\underline{s}_{m m}\right)=0$ by Claim $1,(1)$ implies $G_{m+1 m}(0)>0$. However, then firm $f_{m+1}$ gets a zero payoff by the tie-breaking rule. Thus, 
we have $\underline{s}_{m m}>0$. Since firm $f_{m+1}$ gets a positive expected payoff, there is at least another firm $f_{i}$ with $i \in\{m+2, \ldots, n\}$, which is playing a mixed strategy over an interval including $\left[0, \underline{s}_{m m}\right]$. By repeating the same argument, we have $\underline{s}_{m+1 m}>0$, and $G_{i m}\left(\underline{s}_{m+1 m}\right)>0$. This means that there is a firm $f_{i^{\prime}}$ with $i^{\prime} \in\{i+1, \ldots, n\}$, which is playing a mixed strategy over an interval including $\left[0, \underline{s}_{m+1 m}\right]$. However, there is only a finite number of firms; there is a firm $f_{i^{\prime \prime}}$ with $i^{\prime \prime} \in\{m+1, \ldots, n\}$ and $\underline{s}_{i^{\prime \prime} m}=0$, so we have a contradiction. Hence, $\bar{s}_{m}<s_{m}^{*}$ cannot happen.

Now, we assume $\bar{s}_{m}=s_{m}^{*}=Y_{m+1 m}$. In this case, firm $f_{m+1}$ can make only zero payoff by making such an offer; the winning probability of $f_{m+1}$ by offering to $a_{m}$ anything less than $\bar{s}_{m}=s_{m}^{*}$ must be zero (otherwise, $f_{m+1}$ would not make $\bar{s}_{m}=s_{m}^{*}$ offer). Thus, we conclude that $f_{m+1}$ makes an offer to $a_{m}$ with salary $s_{m}^{*}$ with probability one. Then, firm $f_{m}$ makes an offer to $a_{m}$ with salary $s_{m}^{*}$ with a positive probability. The rest is the same as the former case $(n \leq m)$. We have completed the proof.

Proposition 2. If $n \geq 2, m \geq 2$, and $n<2 m$ then there is no pure strategy equilibrium. $^{22}$

Proof. Suppose that $m \geq n$. In this case, each applicant $a_{j}$ should get at most one offer, since a rejected firm gets zero payoff and $Y_{i j}>0$ for all $f_{i}$ and $a_{j}$. However, this implies that all applicants who receive offers must get zero salaries since there is no competition. Since matrix $Y$ is strictly increasing, any firm which does not get $a_{1}$ has an incentive to make a positive salary offer to $a_{1}$. Thus, this cannot be an equilibrium.

Next suppose that $m<n$. In this case, each applicant $a_{j}$ gets at least one offer. If every applicant is getting exactly one offer with zero salary, then we have a contradiction as we have seen before. Actually, as long as there is an applicant who gets multiple offers, no applicant can get zero salary, since a rejected firm has an incentive to make a positive salary offer to a zero salary applicant. As a result, all applicants must get multiple offers in a pure strategy equilibrium. However, it cannot happen when $n<2 m$.

Proposition 3. In a multistage game, there is a stationary Markov perfect equilibrium path such that in stage $\ell=1, \ldots, \min \{n, m\}, f_{\ell}$ makes an offer with $s_{\ell}^{*}$ to $a_{\ell}$ and $a_{\ell}$ accepts the offer immediately.

\footnotetext{
${ }^{22}$ If $m=1$ and/or $n=1$, then there is a pure strategy equilibrium. If $m=1, f_{1}$ gets $a_{1}$ with salary $Y_{21}$ if $n \geq 2$. If $n=1, f_{1}$ gets $a_{1}$ with a zero salary.
} 
Proof. We need only to show non-profitability of unilateral deviations from the equilibrium path described above. In stage $\ell$, let $F^{\prime} \subseteq F$ and $A^{\prime} \subseteq A$ be active firms and applicants of the game, that is, players who have not exited the game by finalizing contracts. Note that some of $F^{\prime}$ might have made offers to applicants before stage $\ell$, and some of them might have been rejected, and others might be outstanding in stage $\ell$. However, since we are considering the supportability of a path against unilateral deviation, we do not need to exhaust all possible states. State $\left(F^{\prime}, A^{\prime}\right)$ describes the situation where $F \backslash F^{\prime}$ and $A \backslash A^{\prime}$ have already been matched up, and $F^{\prime}$ and $A^{\prime}$ are the only active players, and there is no rejected offer or pending offer among $F^{\prime}$ and $A^{\prime}$. We also consider states with rejected offers and states with pending offers. An example of the former is $\left(F^{\prime}, A^{\prime},(f, a)\right)$ : the contents of the inner () is a rejected offer which shows that $a$ rejected $f$ 's offer and $f$ will not be able to make another offer to $a$ (after being rejected, the amount of the salary does not matter, so is omitted. If there are multiple rejected offers, then a list of rejected offers follows after $\left(F^{\prime}, A^{\prime}\right)$. An example of the latter one is $\left(F^{\prime}, A^{\prime} ;\langle f, a, s\rangle\right)$ : the contents of \langle\rangle is a pending offer which shows that $f$ made an offer to $a$ with a salary $s$ but $a$ has not accepted or rejected it. As before, if there are multiple pending offers then a list of pending offers follows $\left(F^{\prime}, A^{\prime}\right)$. In order to describe all possible states, we need to list both the set of rejected offers and the one of pending offers after the set of active players. However, since we are interested in the nonprofitability of unilateral deviations, we do not need to introduce full notation.

Let $s^{*}\left(F^{\prime}, A^{\prime}\right)$ be the minimum competitive equilibrium salary vector for an assignment problem $\left(F^{\prime}, A^{\prime}\right)$, where the production matrix used is $\left.Y\right|_{F^{\prime}, A^{\prime}}$ which is a restriction of the production matrix $Y$ on $\left(F^{\prime}, A^{\prime}\right)$ : this matrix is also strictly supermodular and strictly increasing; thus we can apply Lemma 1 for $s^{*}\left(F^{\prime}, A^{\prime}\right)$.

Now, we describe players' strategies in relevant states.

\section{Firms' strategies in relevant states.}

We let only one firm make an offer in each case.

1. If there is no rejected offer nor pending offer at a state, then $f_{1}\left(F^{\prime}\right)$ makes an offer to $a_{1}\left(A^{\prime}\right)$ with salary $s_{1}^{*}\left(F^{\prime}, A^{\prime}\right)$.

2. If a state involves a rejected offer $(f, a)=\left(f_{1}\left(F^{\prime}\right), a_{1}\left(A^{\prime}\right)\right),{ }^{23}$ then $f_{2}\left(F^{\prime}\right)$

\footnotetext{
${ }^{23}$ Given the applicants' strategies, rejection can occur only by $a_{1}\left(A^{\prime}\right)$ with unilateral
} 
makes an offer to $a_{1}\left(A^{\prime}\right)$ with salary ${ }^{24}$

$$
s_{1}^{*}\left(F^{\prime}, A^{\prime} ;\left(f_{1}\left(F^{\prime}\right), a_{1}\left(A^{\prime}\right)\right)\right)=\left.Y_{3,1}\right|_{F^{\prime}, A^{\prime}}-\left.Y_{3,3}\right|_{F^{\prime}, A^{\prime}}+s_{3}^{*}\left(F^{\prime}, A^{\prime}\right) .
$$

3. If a state involves a pending offer $\langle f, a, s\rangle$, then there are five cases. ${ }^{25}$

(a) If $\langle f, a, s\rangle=\left\langle f_{1}\left(F^{\prime}\right), a_{1}\left(A^{\prime}\right), s_{1}\right\rangle$ with $s_{1}<s_{1}^{*}\left(F^{\prime}, A^{\prime}\right)$ then $f_{2}\left(F^{\prime}\right)$ makes an offer to $a_{1}\left(A^{\prime}\right)$ with salary $\max \left\{s_{1}+\epsilon, s_{3}^{*}\left(F^{\prime}, A^{\prime}\right)+\left.Y_{3,1}\right|_{F^{\prime}, A^{\prime}}-\right.$ $\left.\left.Y_{33}\right|_{F^{\prime}, A^{\prime}}\right\},{ }^{26}$ where $\epsilon>0$ is a small number.

(b) If $\langle f, a, s\rangle=\left\langle f_{2}\left(F^{\prime}\right), a_{1}\left(A^{\prime}\right), s_{1}\right\rangle$ with $s_{1} \leq s_{1}^{*}\left(F^{\prime}, A^{\prime}\right)$ then $f_{1}\left(F^{\prime}\right)$ makes an offer to $a_{1}\left(A^{\prime}\right)$ with salary $\max \left\{s_{1}, s_{3}^{*}\left(F^{\prime}, A^{\prime}\right)+\left.Y_{3,1}\right|_{F^{\prime}, A^{\prime}}-\right.$ $\left.\left.Y_{33}\right|_{F^{\prime}, A^{\prime}}\right\}$.

(c) If $\langle f, a, s\rangle=\left\langle f_{k}\left(F^{\prime}\right), a_{k}\left(A^{\prime}\right), s_{k}\right\rangle$ with $s_{k}<s_{k}^{*}\left(F^{\prime}, A^{\prime}\right)$ then $f_{1}\left(F^{\prime}\right)$ makes an offer to $a_{1}\left(A^{\prime}\right)$ with salary $s_{1}^{*}\left(F^{\prime}, A^{\prime}\right)-s_{k}^{*}\left(F^{\prime}, A^{\prime}\right)+$ $\max \left\{s_{k}+\epsilon, s_{k+2}^{*}\left(F^{\prime}, A^{\prime}\right)+\left.Y_{k+2, k}\right|_{F^{\prime}, A^{\prime}}-\left.Y_{k+2, k+2}\right|_{F^{\prime}, A^{\prime}}\right\}$, where $\epsilon>0$ is a small number. (Firm $f_{1}\left(F^{\prime}\right)$ arrives at this by expecting that $f_{k+1}\left(F^{\prime}\right)$ will make an offer to $a_{k}\left(A^{\prime}\right)$ with salary $s_{k}^{\prime}=\max \left\{s_{k}+\right.$ $\left.\epsilon, s_{k+2}^{*}\left(F^{\prime}, A^{\prime}\right)+\left.Y_{k+2, k}\right|_{F^{\prime}, A^{\prime}}-\left.Y_{k+2, k+2}\right|_{F^{\prime}, A^{\prime}}\right\}$ at the $k$ th stage from now. At the $k+1$ th stage from now, rejected $f_{k}\left(F^{\prime}\right)$ will make an offer to $a_{k+1}\left(A^{\prime}\right)$ with salary $s_{k+1}^{*}\left(F^{\prime}\right)$.)

(d) If $\langle f, a, s\rangle=\left\langle f_{k+1}\left(F^{\prime}\right), a_{k}\left(A^{\prime}\right), s_{k}\right\rangle$ with $s_{k} \leq s_{k}^{*}\left(F^{\prime}, A^{\prime}\right)$ then $f_{1}\left(F^{\prime}\right)$ makes an offer to $a_{1}\left(A^{\prime}\right)$ with salary $s_{1}^{*}\left(F^{\prime}, A^{\prime}\right)-s_{k}^{*}\left(F^{\prime}, A^{\prime}\right)+$ $\max \left\{s_{k}, s_{k+2}^{*}\left(F^{\prime}, A^{\prime}\right)+\left.Y_{k+2, k}\right|_{F^{\prime}, A^{\prime}}-\left.Y_{k+2, k+2}\right|_{F^{\prime}, A^{\prime}}\right\}$. (Firm $f_{1}\left(F^{\prime}\right)$ arrives at this by expecting that $f_{k}\left(F^{\prime}\right)$ will make an offer to $a_{k}\left(A^{\prime}\right)$

deviations. Thus, we can focus on rejections by $a_{1}\left(A^{\prime}\right)$ only. If there are multiple rejections by $a_{1}\left(A^{\prime}\right),\left(f_{1}\left(F^{\prime}\right), a_{1}\left(A^{\prime}\right)\right), \ldots,\left(f_{i}\left(F^{\prime}\right), a_{1}\left(A^{\prime}\right)\right)$, then $f_{i+1}\left(F^{\prime}\right)$ makes an offer to $a_{1}\left(A^{\prime}\right)$ with salary

$$
\begin{aligned}
& s_{1}^{*}\left(F^{\prime}, A^{\prime} ;\left(f_{1}\left(F^{\prime}\right), a_{1}\left(A^{\prime}\right)\right), \ldots,\left(f_{i}\left(F^{\prime}\right), a_{1}\left(A^{\prime}\right)\right)\right) \\
= & s_{i+2}^{*}\left(F^{\prime}, A^{\prime}\right)+\left(\left.Y_{i+2,1}\right|_{F^{\prime}, A^{\prime}}-\left.Y_{i+2, i+2}\right|_{F^{\prime}, A^{\prime}}\right) .
\end{aligned}
$$

${ }^{24}$ After $f_{1}\left(F^{\prime}\right)$ being rejected by $a_{1}\left(A^{\prime}\right), f_{2}\left(F^{\prime}\right)$ 's only direct competitor is $f_{3}\left(F^{\prime}\right)$. Thus, $f_{2}\left(F^{\prime}\right)$ can get $a_{1}\left(A^{\prime}\right)$ if $f_{3}\left(F^{\prime}\right)$ would rather get $a_{3}\left(A^{\prime}\right)$. Note that $a_{2}\left(A^{\prime}\right)$ would be taken by $f_{1}\left(F^{\prime}\right)$.

${ }^{25}$ Even if there are multiple pending offers, we let the best available applicant receive an offer from the best available firm without a pending offer in a similar manner.

${ }^{26} \mathrm{Firm} f_{1}\left(F^{\prime}\right)$ can beat $f_{2}\left(F^{\prime}\right)$ by offering $s_{1}$. However, $f_{1}\left(F^{\prime}\right)$ needs to worry about $f_{3}\left(F^{\prime}\right)$ challenging to get $a_{1}\left(A^{\prime}\right)$. 
with salary $\max \left\{s_{k}, s_{k+2}^{*}\left(F^{\prime}, A^{\prime}\right)+\left.Y_{k+2, k}\right|_{F^{\prime}, A^{\prime}}-\left.Y_{k+2, k+2}\right|_{F^{\prime}, A^{\prime}}\right\}$ at the $k$ th stage from now.)

(e) If a pending offer takes any other form, $f_{1}\left(A^{\prime}\right)$ makes an offer to $a_{1}\left(A^{\prime}\right)$ with salary $s_{1}^{*}\left(F^{\prime}, A^{\prime}\right) .{ }^{27}$

\section{Applicants' strategies in relevant states.}

1. Suppose that there is no rejected offer at the state.

(a) If applicant $a_{1}\left(A^{\prime}\right)$ receives offers with a salary more than or equal to $s_{1}^{*}\left(F^{\prime}, A^{\prime}\right)$, then she chooses the highest salary offer and immediately accepts it (for multiple highest salary offers, choose the smallest index firm).

(b) If applicant $a_{1}\left(A^{\prime}\right)$ receives offers with the highest salary $s_{1}^{\prime}<$ $s_{1}^{*}\left(F^{\prime}, A^{\prime}\right)$ or with the highest salary $s_{1}^{\prime}=s_{1}^{*}\left(F^{\prime}, A^{\prime}\right)$ from $f \neq$ $f_{1}\left(F^{\prime}\right)$, then she keeps the best offer and waits for a better offer until there is no other available firm $f \in F^{\prime}$ (which has not been rejected by $a_{1}\left(A^{\prime}\right)$ or has a pending offer to another applicant).

(c) If applicant $a_{i}\left(A^{\prime}\right)(i \neq 1)$ receives offers, then she keeps the best offer and waits for a better offer until $a_{i}\left(A^{\prime}\right)$ becomes the top applicant $a_{1}\left(A^{\prime \prime}\right)$ among $A^{\prime \prime} \subset A^{\prime}$ after some states pass (then one of the cases 1.a. or 1.b. applies), or until the game ends due to there being no proposer at the stage.

2. Suppose that there is a rejected offer. ${ }^{28}$ The only relevant case is that $a_{1}\left(A^{\prime}\right)$ deviated at the last stage by rejecting the offer from $f_{1}\left(F^{\prime}\right)$. In this case, if $f_{2}\left(F^{\prime}\right)$ offers to $a_{1}\left(A^{\prime}\right)$ salary

$$
s_{1}^{*}\left(F^{\prime}, A^{\prime} ;\left(f_{1}\left(F^{\prime}\right), a_{1}\left(A^{\prime}\right)\right)\right)=s_{3}^{*}\left(F^{\prime}, A^{\prime}\right)+\left(\left.Y_{3,1}\right|_{F^{\prime}, A^{\prime}}-\left.Y_{3,3}\right|_{F^{\prime}, A^{\prime}}\right),
$$

\footnotetext{
${ }^{27}$ As a result, unless a pending offer $\langle f, a, s\rangle=\left\langle f_{i}, a_{j}, s_{j}\right\rangle$ satisfies $i=j$ or $i=j+1$, it is irrelevant in determining salary.

${ }^{28}$ Similarly, if in case $a_{1}\left(A^{\prime}\right)$ rejected multiple offers $\left(f_{1}\left(F^{\prime}\right), a_{1}\left(A^{\prime}\right)\right),\left(f_{2}\left(F^{\prime}\right), a_{1}\left(A^{\prime}\right)\right)$, $\ldots,\left(f_{i}\left(F^{\prime}\right), a_{1}\left(A^{\prime}\right)\right)$, and if $f_{i+1}\left(F^{\prime}\right)$ offers $a_{1}\left(A^{\prime}\right)$ with salary

$$
\begin{aligned}
& s_{1}^{*}\left(F^{\prime}, A^{\prime} ;\left(f_{1}\left(F^{\prime}\right), a_{1}\left(A^{\prime}\right)\right), \ldots,\left(f_{i}\left(F^{\prime}\right), a_{1}\left(A^{\prime}\right)\right)\right) \\
= & s_{i+2}^{*}\left(F^{\prime}, A^{\prime}\right)+\left(\left.Y_{i+2,1}\right|_{F^{\prime}, A^{\prime}}-\left.Y_{i+2, i+2}\right|_{F^{\prime}, A^{\prime}}\right),
\end{aligned}
$$
}

then $a_{1}\left(A^{\prime}\right)$ accepts the offer. 
then $a_{1}\left(A^{\prime}\right)$ accepts the offer immediately.

3. Suppose that there is a pending offer $\langle f, a, s\rangle$.

(a) If $\langle f, a, s\rangle=\left\langle f_{1}\left(F^{\prime}\right), a_{1}\left(A^{\prime}\right), s_{1}\right\rangle$ with $s_{1}<s_{1}^{*}\left(F^{\prime}, A^{\prime}\right)$ and if $f_{2}\left(F^{\prime}\right)$ makes an offer to $a_{1}\left(A^{\prime}\right)$ with salary more than or equal to $\max \left\{s_{1}+\right.$ $\left.\epsilon, s_{3}^{*}\left(F^{\prime}, A^{\prime}\right)+\left.Y_{3,1}\right|_{F^{\prime}, A^{\prime}}-\left.Y_{33}\right|_{F^{\prime}, A^{\prime}}\right\}$, where $\epsilon>0$ is a small number, then $a_{1}\left(A^{\prime}\right)$ accepts it immediately.

(b) If $\langle f, a, s\rangle=\left\langle f_{2}\left(F^{\prime}\right), a_{1}\left(A^{\prime}\right), s_{1}\right\rangle$ with $s_{1} \leq s_{1}^{*}\left(F^{\prime}, A^{\prime}\right)$ and if $f_{1}\left(F^{\prime}\right)$ makes an offer to $a_{1}\left(A^{\prime}\right)$ with salary more than or equal to $\max \left\{s_{1}, s_{3}^{*}\left(F^{\prime}, A^{\prime}\right)+\right.$ $\left.\left.Y_{3,1}\right|_{F^{\prime}, A^{\prime}}-\left.Y_{33}\right|_{F^{\prime}, A^{\prime}}\right\}$, then $a_{1}\left(A^{\prime}\right)$ accepts it immediately.

(c) If $\langle f, a, s\rangle=\left\langle f_{k}\left(F^{\prime}\right), a_{k}\left(A^{\prime}\right), s_{k}\right\rangle$ with $s_{k}<s_{k}^{*}\left(F^{\prime}, A^{\prime}\right)$ and if $f_{1}\left(F^{\prime}\right)$ makes an offer to $a_{1}\left(A^{\prime}\right)$ with salary more than or equal to $s_{1}^{*}\left(F^{\prime}, A^{\prime}\right)$ $s_{k}^{*}\left(F^{\prime}, A^{\prime}\right)+\max \left\{s_{k}+\epsilon, s_{k+2}^{*}\left(F^{\prime}, A^{\prime}\right)+\left.Y_{k+2, k}\right|_{F^{\prime}, A^{\prime}}-\left.Y_{k+2, k+2}\right|_{F^{\prime}, A^{\prime}}\right\}$, where $\epsilon>0$ is a small number, then $a_{1}\left(A^{\prime}\right)$ accepts it immediately.

(d) If $\langle f, a, s\rangle=\left\langle f_{k+1}\left(F^{\prime}\right), a_{k}\left(A^{\prime}\right), s_{k}\right\rangle$ with $s_{k} \leq s_{k}^{*}\left(F^{\prime}, A^{\prime}\right)$ and if $f_{1}\left(F^{\prime}\right)$ makes an offer to $a_{1}\left(A^{\prime}\right)$ with salary more than or equal to $s_{1}^{*}\left(F^{\prime}, A^{\prime}\right)-s_{k}^{*}\left(F^{\prime}, A^{\prime}\right)+\max \left\{s_{k}, s_{k+2}^{*}\left(F^{\prime}, A^{\prime}\right)+\left.Y_{k+2, k}\right|_{F^{\prime}, A^{\prime}}-\right.$ $\left.\left.Y_{k+2, k+2}\right|_{F^{\prime}, A^{\prime}}\right\}$, then $a_{1}\left(A^{\prime}\right)$ accepts it immediately.

(e) If a pending offer takes any other form, and if $f_{1}\left(A^{\prime}\right)$ makes an offer to $a_{1}\left(A^{\prime}\right)$ with salary more than or equal to $s_{1}^{*}\left(F^{\prime}, A^{\prime}\right)$, then $a_{1}\left(A^{\prime}\right)$ accepts it immediately.

The above strategy profile generates the equilibrium path. in stage $\ell$, $f_{1}\left(F^{\prime}\right)$ and $a_{1}\left(A^{\prime}\right)$ are matched, and in stage $\ell+1$, the game is played by $F^{\prime} \backslash\left\{f_{1}\left(F^{\prime}\right)\right\}$ and $A^{\prime} \backslash\left\{a_{1}\left(A^{\prime}\right)\right\}$, and the above strategies apply to this subgame, too. It is easy to see that the above strategies generate the simple path of firm $f_{\ell}$ making an offer to $a_{\ell}$ with salary $s_{\ell}^{*}\left(F^{\prime}, A^{\prime}\right)$ for all $\ell=1, \ldots, n$, and of applicants accepting offers immediately.

Given the above on-equilibrium strategies, the following cases may occur by having a unilateral deviation by a firm.

1. Firm $f_{1}\left(F^{\prime}\right)$ deviates at a stage. There are three cases.

(a) $f_{1}\left(F^{\prime}\right)$ does not make an offer. In this case, the game ends, and $f_{1}\left(F^{\prime}\right)$ gets zero payoff. Thus, there is no such incentive. 
(b) $f_{1}\left(F^{\prime}\right)$ makes an offer to $a_{j}\left(A^{\prime}\right)$ with $j \neq 1$. In this case, if the salary is more than or equal to $s_{j}^{*}\left(F^{\prime}, A^{\prime}\right)$ then $a_{j}\left(A^{\prime}\right)$ accepts the offer eventually (after all applicants who are better than $a_{j}\left(A^{\prime}\right)$ have accepted offers). Thus, $f_{1}\left(F^{\prime}\right)$ and $a_{j}\left(A^{\prime}\right)$ are matched and they exit the game. However, $f_{1}\left(F^{\prime}\right)$ 's payoff is lower than on-equilibrium outcome: $f_{1}\left(F^{\prime}\right)$ being matched with $a_{1}\left(A^{\prime}\right)$ with salary $s_{1}^{*}\left(F^{\prime}, A^{\prime}\right)$. It is because $\mathbf{s}^{*}\left(F^{\prime}, A^{\prime}\right)$ is a competitive salary vector. If the salary is less than $s_{j}^{*}\left(F^{\prime}, A^{\prime}\right)$ then the offer is eventually rejected, and at this stage the best available applicant is $a_{j+1}\left(A^{\prime}\right)$, who demands $s_{j+1}^{*}\left(F^{\prime}, A^{\prime}\right)$. Thus, again $f_{1}\left(F^{\prime}\right)$ 's payoff is lowered because $\mathbf{s}^{*}\left(F^{\prime}, A^{\prime}\right)$ is a competitive salary vector.

(c) $f_{1}\left(F^{\prime}\right)$ makes an offer to $a_{1}\left(A^{\prime}\right)$ with salary $s_{1}$ that is less than $s_{1}^{*}\left(F^{\prime}, A^{\prime}\right)$. (If more, then the offer will be accepted immediately, and $f_{1}\left(F^{\prime}\right)$ is worse off.) In this case, $a_{1}\left(A^{\prime}\right)$ does not accept the offer immediately, and $f_{1}\left(F^{\prime}\right)$ cannot make any offer at this stage due to the outstanding offer. In this subgame $\left.\left\langle f_{1}\left(F^{\prime}\right), a_{1}\left(A^{\prime}\right), s_{1}\right\rangle\right)$, the on-equilibrium path is described in the following way. $f_{2}\left(F^{\prime}\right)$ makes an offer to $a_{1}\left(A^{\prime}\right)$ with salary $\max \left\{s_{1}, s_{1}^{*}\left(F^{\prime} \backslash\left\{f_{1}\left(F^{\prime}\right)\right\}, A^{\prime}\right)\right.$, and $a_{1}\left(A^{\prime}\right)$ accepts the offer from $f_{2}\left(F^{\prime}\right)$ immediately. ${ }^{29}$ The rest of the game is played by $F^{\prime} \backslash\left\{f_{2}\left(F^{\prime}\right)\right\}$ and $A^{\prime} \backslash\left\{a_{1}\left(A^{\prime}\right)\right\}$, and the on-equilibrium strategies described in the beginning of the proof applies to this subgame, too. Given this, $f_{1}\left(F^{\prime}\right)$ is matched with $a_{2}\left(A^{\prime}\right)$ with salary $s_{1}^{*}\left(F^{\prime} \backslash\left\{f_{2}\left(F^{\prime}\right)\right\}, A^{\prime} \backslash\left\{a_{1}\left(A^{\prime}\right)\right\}\right)=s_{2}^{*}\left(F^{\prime}, A^{\prime}\right)$, and it is apparently not beneficial to $f_{1}\left(F^{\prime}\right)$.

2. Firm $f_{i}\left(F^{\prime}\right)(i \neq 1)$ also makes an offer to an applicant in addition to $f_{1}\left(F^{\prime}\right)$ making an offer to $a_{1}\left(A^{\prime}\right)$. There are two cases.

(a) $f_{i}\left(F^{\prime}\right)$ makes an offer to $a_{j}\left(A^{\prime}\right)$ with $j>i$. If the salary is not more than $s_{j}^{*}\left(F^{\prime}, A^{\prime}\right)$, then the offer is rejected eventually. Moreover, by then, $f_{i}\left(F^{\prime}\right)$ 's natural partner $a_{i}\left(A^{\prime}\right)$ is no longer available. Thus, $f^{\prime}\left(F^{\prime}\right)$ is worse off. If it is more than or equal to $s_{j}^{*}\left(F^{\prime}, A^{\prime}\right)$, then the offer is accepted eventually, but $f_{i}\left(F^{\prime}\right)$ is worse off than in the on-equilibrium outcome.

\footnotetext{
${ }^{29}$ More precisely, $f_{2}\left(F^{\prime}\right)$ needs to make an offer to $a_{1}\left(A^{\prime}\right)$ with a salary slightly higher than $s_{1}^{\prime}$ (due to the tie-breaking rule).
} 
(b) $f_{i}\left(F^{\prime}\right)$ makes an offer to $a_{j}\left(A^{\prime}\right)$ with $j \leq i$. In this case, this offer will be outstanding in stage $\ell$ (if the salary is more than $s_{j}^{*}\left(F^{\prime}, A^{\prime}\right)$ and if it is accepted, and $f_{i}\left(F^{\prime}\right)$ is worse off). If $i-j \geq 2$ (thus, $f_{i}\left(F^{\prime}\right)$ is irrelevant in determining on-equilibrium salary of $\left.a_{j}\left(A^{\prime}\right)\right) f_{j}\left(F^{\prime}\right)$ and $f_{j+1}\left(F^{\prime}\right)$ would compete for $a_{j}\left(A^{\prime}\right)$ potentially by offering $s_{j}^{*}\left(F^{\prime}, A^{\prime}\right)$ in expectation that the rejected $f_{i}\left(F^{\prime}\right)$ makes an offer to $a_{i}\left(A^{\prime}\right)$ following the on-equilibrium strategy. ${ }^{30}$ Thus, firm $f_{i}\left(F^{\prime}\right)$ 's payoff is not affected by this irrelevant offer (except for a cost to make an additional offer). If $i=j$ or $i=j+1$, the resulting salary structure could be affected. Consider the case $i=j$. If the offer is above $s_{j}^{*}\left(F^{\prime}, A^{\prime}\right)$, then $f_{i}\left(F^{\prime}\right)$ is worse off. If the offer is less than that, then $f_{i+1}\left(F^{\prime}\right)$ matches (or pays even more than that if $f_{i+2}\left(F^{\prime}\right)$ is willing to pay the salary that $f_{i}\left(F^{\prime}\right)$ offers: in this case $f_{i+2}\left(F^{\prime}\right)$ is the real competitor for $f_{i+1}\left(F^{\prime}\right)$, so $f_{i+1}\left(F^{\prime}\right)$ needs to pay more to get $\left.a_{j}\left(A^{\prime}\right)\right)$, and $a_{j}\left(A^{\prime}\right)$ accepts $f_{i+1}\left(F^{\prime}\right)$ 's offer. As a result, $f_{i}\left(F^{\prime}\right)$ is worse off. Lastly, consider the case $i=j+1$. If the offered salary is more than or equal to $s_{j}^{*}\left(F^{\prime}, A^{\prime}\right)$, then it is accepted, but $f_{i}\left(F^{\prime}\right)$ is worse off. If the salary is less than $s_{j}^{*}\left(F^{\prime}, A^{\prime}\right)$, then the offer will be outstanding. At the stage when $f_{j}\left(F^{\prime}\right)$ 's turn comes, $f_{j}\left(F^{\prime}\right)$ will offer exactly the same salary as $f_{i}\left(F^{\prime}\right)$ did, and $a_{j}\left(A^{\prime}\right)$ accepts $f_{j}\left(F^{\prime}\right)$ 's offer. Being rejected, $f_{i}\left(F^{\prime}\right)$ will make an offer to $a_{i}\left(A^{\prime}\right)$ with salary $s_{i}^{*}\left(F^{\prime}, A^{\prime}\right)$, ending up with the same payoff as on the equilibrium path (except for the cost for making an additional offer).

Thus, in any case, a unilateral deviation from the equilibrium strategy does not improve firms' payoff. Finally, we need to determine if an applicant has an incentive to deviate from her equilibrium strategy unilaterally. First consider $a_{1}\left(A^{\prime}\right)$. Suppose that $a_{1}\left(A^{\prime}\right)$ gets an on-equilibrium offer $s_{1}^{*}\left(F^{\prime}, A^{\prime}\right)$ from $f_{1}\left(F^{\prime}\right)$, and suppose to the contrary that she rejects the offer. Then, since $f_{1}\left(F^{\prime}\right)$ can no longer make an offer to $a_{1}\left(A^{\prime}\right)$, it goes after $a_{2}\left(A^{\prime}\right)$. Now, firm $f_{2}\left(F^{\prime}\right)$ will have a chance to get $a_{1}\left(A^{\prime}\right)$, and its primary competitor is $f_{3}\left(A^{\prime}\right)$. Thus, $f_{2}\left(F^{\prime}\right)$ can offer $a_{1}\left(A^{\prime}\right)$ a salary $s_{21}^{\prime}=$ $Y_{31}\left(F^{\prime}, A^{\prime}\right)-Y_{33}\left(F^{\prime}, A^{\prime}\right)+s_{3}^{*}\left(F^{\prime}, A^{\prime}\right)$. With this offer, $f_{2}\left(F^{\prime}\right)$ obtains payoff (if accepted) $Y_{21}\left(F^{\prime}, A^{\prime}\right)-s_{21}^{\prime}=Y_{21}\left(F^{\prime}, A^{\prime}\right)-Y_{31}\left(F^{\prime}, A^{\prime}\right)+Y_{33}\left(F^{\prime}, A^{\prime}\right)-s_{3}^{*}\left(F^{\prime}, A^{\prime}\right)$. By strict supermodularity, this is higher than $Y_{22}\left(F^{\prime}, A^{\prime}\right)-s_{2}^{*}\left(F^{\prime}, A^{\prime}\right)=$

\footnotetext{
${ }^{30}$ If $f_{i}\left(F^{\prime}\right)$ is better off by deviating at the stage of making an offer to $a_{i}\left(A^{\prime}\right)$, then she can also be better off by deviation at that stage alone.
} 
$Y_{22}\left(F^{\prime}, A^{\prime}\right)-Y_{32}\left(F^{\prime}, A^{\prime}\right)+Y_{33}\left(F^{\prime}, A^{\prime}\right)-s_{3}^{*}\left(F^{\prime}, A^{\prime}\right)$. Thus, firm $f_{2}\left(F^{\prime}\right)$ indeed makes an offer to $a_{1}\left(A^{\prime}\right)$ instead of $a_{2}\left(A^{\prime}\right)$ (if $s_{21}^{\prime}$ would be accepted). Now, let us focus on $a_{1}\left(A^{\prime}\right)$ 's payoff. If $a_{1}\left(A^{\prime}\right)$ accepted the offer from $f_{1}\left(F^{\prime}\right)$ then she gets $s_{1}^{*}\left(F^{\prime}, A^{\prime}\right)$, and if she accepts the offer from $a_{2}\left(A^{\prime}\right)$, then she gets $s_{21}^{\prime}=Y_{31}\left(F^{\prime}, A^{\prime}\right)-Y_{33}\left(F^{\prime}, A^{\prime}\right)+s_{3}^{*}\left(F^{\prime}, A^{\prime}\right)$. However, by strict supermodularity and strict increasingness, it is easy to see

$$
\begin{aligned}
& s_{1}^{*}\left(F^{\prime}, A^{\prime}\right) \\
= & Y_{21}\left(F^{\prime}, A^{\prime}\right)-Y_{22}\left(F^{\prime}, A^{\prime}\right)+s_{2}^{*}\left(F^{\prime}, A^{\prime}\right) \\
= & Y_{21}\left(F^{\prime}, A^{\prime}\right)-Y_{22}\left(F^{\prime}, A^{\prime}\right)+Y_{32}\left(F^{\prime}, A^{\prime}\right)-Y_{33}\left(F^{\prime}, A^{\prime}\right)+s_{3}^{*}\left(F^{\prime}, A^{\prime}\right) \\
> & Y_{31}\left(F^{\prime}, A^{\prime}\right)-Y_{33}\left(F^{\prime}, A^{\prime}\right)+Y_{32}\left(F^{\prime}, A^{\prime}\right)-Y_{33}\left(F^{\prime}, A^{\prime}\right)+s_{3}^{*}\left(F^{\prime}, A^{\prime}\right) \\
> & Y_{31}\left(F^{\prime}, A^{\prime}\right)-Y_{33}\left(F^{\prime}, A^{\prime}\right)+s_{3}^{*}\left(F^{\prime}, A^{\prime}\right)=s_{21}^{\prime} .
\end{aligned}
$$

This implies that $a_{1}\left(F^{\prime}, A^{\prime}\right)$ does not have an incentive to reject an offer $s_{1}^{*}\left(F^{\prime}, A^{\prime}\right)$ from $f_{1}\left(F^{\prime}\right) .{ }^{31}$ It is easy to see that it does not make sense for $a_{j}\left(A^{\prime}\right)$ to reject an offer of a salary more than or equal to $s_{j}^{*}\left(F^{\prime}, A^{\prime}\right)$. If an offer is made by $f_{i}\left(F^{\prime}\right)$ with $i<j$, and if the salary is lower than $s_{j}^{*}\left(F^{\prime}, A^{\prime}\right)$, then there is no reason to hold such an offer. By waiting, she will receive an offer from $f_{j}\left(F^{\prime}, A^{\prime}\right)$ with salary $s_{j}^{*}\left(F^{\prime}, A^{\prime}\right)$. Thus, rejecting such an offer immediately does not alter her payoff. Finally, if an offer is made by $f_{i}\left(F^{\prime}\right)$ with $i=j$ or $j+1$ with salary lower than $s_{j}^{*}\left(F^{\prime}, A^{\prime}\right)$, then she has no incentive to reject such an offer. Rejecting an offer is a weakly dominated strategy since it reduces the number of relevant competitors. This proves that applicants also have no incentive to deviate from the strategy profile unilaterally.

Proposition 4. Suppose $n \geq 2$ and $m \geq 2$. In a multistage game, in any pure strategy stationary Markov perfect equilibrium without any rejection on the equilibrium path, the equilibrium salary vector satisfies $\mathbf{s} \leq \mathbf{s}^{*}$, and firms' payoff vector satisfies $\mathbf{u} \geq \mathbf{u}^{*}$, where $u_{i}^{*}=Y_{i i}-s_{i}^{*}$ for all $f_{i} \in F$.

Proof of Proposition 4. By induction. First, note that if $|F|=2$, then equilibrium salary vector $\mathbf{s}$ satisfies $\mathbf{s} \leq \mathbf{s}^{*}$, because there are only two equilibrium salary vectors: one is $\mathbf{s}^{*}$ and the other is $\mathbf{s}=\left(Y_{31}, Y_{32}\right)$ if $|A| \geq 3$ and

\footnotetext{
${ }^{31}$ Here, we assume that $a_{1}\left(A^{\prime}\right)$ would accept an offer $s_{21}^{\prime}$ from $f_{2}\left(F^{\prime}\right)$ in the case where she rejected an offer $s_{1}^{*}\left(F^{\prime}, A^{\prime}\right)$ from $f_{1}\left(F^{\prime}\right)$. It is easy to see if $a_{1}\left(A^{\prime}\right)$ rejects this offer as well, then she would be even more worse off.
} 
$\mathbf{s}=(0,0)$ if $|A|=2$ (see Example 3). In order to show that there is no other equilibrium, we show that a non-assortative matching cannot be an equilibrium outcome when $|F|=2$. This can be seen as follows. If $f_{1}$ is matched with $a_{2}, f_{2}$ must be matched with $a_{1}$. Since $f_{1}$ does not counter the offer by $f_{2}$ to $a_{1}, f_{1}$ must make its offer first. The salary offer for this case is $s_{2}=s_{2}^{*}$ : $s_{2}^{*}=Y_{32}$ if $m \geq 3$ ( $s_{2}^{*}=0$ otherwise). Once $f_{1}$ makes an offer to $a_{2}$, then $f_{2}$ 's only rival is $f_{3}$, so $s_{1}=Y_{31}$ if $m \geq 3$ ( $s_{1}=0$ otherwise). In this allocation, $f_{1}$ 's payoff is $Y_{12}-Y_{32}$, while if $f_{1}$ gets $a_{1}$ with salary $s_{1}^{*}=Y_{21}-Y_{22}+Y_{32}$, its payoff is $Y_{11}-s_{1}^{*}=Y_{11}-Y_{21}+Y_{22}-Y_{32}$. However, by subtracting the former from the latter, we have

$$
\begin{aligned}
Y_{11}-s_{1}^{*}-\left(Y_{12}-s_{2}^{*}\right) & =Y_{11}-Y_{21}+Y_{22}-Y_{32}-\left(Y_{12}-Y_{32}\right) \\
& =Y_{11}-Y_{12}-\left(Y_{21}-Y_{22}\right) \\
& >0
\end{aligned}
$$

by strict supermodularity. Thus, there are only two equilibria with the assortative matching with $\mathbf{s} \leq \mathbf{s}^{*}$, and we have $\mathbf{u} \geq \mathbf{u}^{*}$ in all equilibria. ${ }^{32}$ Thus, the induction hypothesis is satisfied when $|F|=2$.

Suppose that for all games $(F, A)$ with $|F|<k$, all equilibria have $\mathbf{s} \leq \mathbf{s}^{*}$ and $\mathbf{u} \geq \mathbf{u}^{*}$. Consider a game $(F, A)$ with $|F|=k$. Suppose that there is an equilibrium without rejections on the equilibrium path in which $a_{j}$ receives $s_{j}>s_{j}^{*}$. Then, there is a firm $f_{i}$ matched with $a_{j}$. Let $\left(F^{\prime}, A^{\prime}\right)$ be the set of active players when $f_{i}$ makes an offer to $a_{j} .{ }^{33}$ There are two cases: $i=j$ or $i \neq j$. First assume that $i=j$. Then, $s_{i}>s_{i}^{*}$, and there is a firm $f_{i^{\prime}} \in F^{\prime}$ which has an incentive to make an offer to $a_{i}$ instead of its equilibrium partner, say, $a_{j^{\prime}}$. That is, $u_{i^{\prime}}=Y_{i^{\prime} i}-s_{i}<Y_{i^{\prime} i}-s_{i}^{*} \leq u_{i^{\prime}}^{*}$. Suppose that firm $f_{i^{\prime}}$ makes an offer to $a_{j^{\prime}}$ with salary $s_{j^{\prime}}=Y_{i^{\prime} j^{\prime}}-Y_{i^{\prime} i}+s_{i}$ in the same stage that $f_{i}$ makes the offer to $a_{i}$. This cannot be an equilibrium since both parties have incentives to reduce salaries. Thus, $f_{i^{\prime}}$ makes its offer in a later stage with an active player. However, by the induction argument, when $f_{i^{\prime}} \in F^{\prime} \backslash\left\{f_{i}\right\}$ obtains $u_{i^{\prime}} \geq u_{i^{\prime}}^{*}$ in the subgame when $f_{i^{\prime}}$ makes an offer (the number of active players is less than $k$ ). This is a contradiction. Second, assume $i \neq j$. If $a_{i} \in A^{\prime}$, then $f_{i}$ can make an offer to $a_{i}$ instead of $a_{j}$. Since $u_{i}<Y_{i j}-s_{j}^{*} \leq u_{i}^{*}=Y_{i i}-s_{i}^{*}$, then $f_{i}$ prefers making an offer to $a_{i}$ with $s_{i}^{*}$,

\footnotetext{
${ }^{32}$ As is shown in Example 5, if $|F| \neq 2$, a non-assortative matching can be an equilibrium.

${ }^{33}$ Since there is no rejection on equilibrium path, firms that have made offers in the past will not be able to make offers. Thus, $F^{\prime}$ can be considered as the set of firms that have not made offers.
} 
if it were accepted by $a_{i}$. Thus, if $f_{i}$ chooses $a_{j}$ this means that $f_{i}$ 's offer to $a_{i}$ with $s_{i}^{*}$ would be countered by some $f_{i^{\prime}} \in F^{\prime}$. Such $f_{i^{\prime}}$ obtains payoff $Y_{i^{\prime} i}-s_{i}^{*} \leq Y_{i^{\prime} i^{\prime}}-s_{i^{\prime}}^{*}=u_{i^{\prime}}^{*}$. Since $f_{i^{\prime}}$ needs to have an opportunity to make an counter offer, it does not make an offer to its equilibrium partner in the same stage that $f_{i}$ makes an offer. By the induction hypothesis, $u_{i^{\prime}} \geq u_{i^{\prime}}^{*}$, and the only possible case for this is that $Y_{i^{\prime} i}-s_{i}^{*}=Y_{i^{\prime} i^{\prime}}-s_{i^{\prime}}^{*}$. This implies $i^{\prime}=i+1$, and $i<i^{\prime}$. However, then $f_{i^{\prime}}$ cannot make an acceptable counteroffer to $a_{i}$. This is a contradiction. Thus, $\mathbf{s} \leq \mathbf{s}^{*}$ must hold. Now, we show $\mathbf{u} \geq \mathbf{u}^{*}$. Since $\mathbf{s} \leq \mathbf{s}^{*}$, if there is $f_{i}$ with $u_{i}<u_{i}^{\prime}$, it must be matched with $a_{j}$ with $j>i$. However, $f_{i}$ can make an offer to $a_{i}$ with $s_{i}^{*}$, which would be accepted by $a_{i}$. This is because if any other firm makes a counteroffer, then that firm's payoff would be lower by the induction hypothesis. This is a contradiction. Thus, we conclude $\mathbf{s} \leq \mathbf{s}^{*}$ and $\mathbf{u} \geq \mathbf{u}^{*}$ for $(F, A)$ with $|F|=k$.

By an induction argument, we complete the proof.

\section{References}

[1] Alcalde, José, David Pérez-Castrillo, and Antonio Romero-Medina "Hiring Procedures to Implement Stable Allocations" Journal of Economic Theory 82, 1998, pp. 469-480.

[2] Bloch, Francis "Sequential Formation of Coalitions in Games with Externalities and Fixed Payoff Division" Games and Economic Behavior 14, 1996, pp. 90-123.

[3] Bloch, Francis, and Effrosyni Diamantoudi "Noncooperative Formation of Coalitions in Hedonic Games" Working Paper, GREQAM, 2006.

[4] Bulow, Jeremy, and Jonathan Levin "Matching and Price Competition" American Economic Review 96, 2006, pp. 652-668.

[5] Chatterjee, Kalayan, Bhaskar Dutta, Debraj Ray, and Kunal Sengupta, "A Noncooperative Theory of Coalitional Bargaining" Review of Economic studies 60, 1993, pp. 175-190.

[6] Demange, Gabrielle, David Gale, and Marilda Sotomayor "Multi-Item Auctions" Journal of Political Economy 94(4), August 1986, pp. 863872 . 
[7] Gale, David, and Lloyd Shapley "College Admissions and Stability of Marriage" American Mathematics Monthly 69, 1962, pp. 9-15.

[8] Gale, Douglas and Hamid Sabourian "Markov Equilibria in Dynamic Matching and Bargaining Games" Games and Economic Behavior 54, 2006, pp. 336-352.

[9] Hayashi, Takashi, and Toyotaka Sakai "Nash Implementation of Competitive Equilibria in the Job-Matching Market" Working Paper, University of Texas, December 2004.

[10] Kelso, Alexander S., and Vincent P. Crawford "Job Matching, Coalition Formation, and Gross Substitutes" Econometrica 50, 1982, pp. 14831504 .

[11] Kojima, Fuhito "Matching and Price Competition When Firms Can Hire More Than One Worker" forthcoming in American Economic Review, 2006.

[12] Niederle, Muriel "Competitive Wages in a Match with Ordered Contracts" forthcoming in American Economic Review, 2007.

[13] Niederle, Muriel, and Alvin E. Roth "Making Markets Thick: Designing Rules for Offers and Acceptances" Working Paper Stanford University, May 2007.

[14] Niederle, Muriel, Alvin E. Roth, and Utku Ünver "Unraveling Results from Comparable Demand and Supply" Working Paper, Harvard University, 2006.

[15] Okada, Akira "A Noncooperative Coalition Bargaining Game with Random Proposers" Games and Economic Behavior 16, 1996, pp. 97-108.

[16] Ray, Debraj, and Rajiv Vohra "A Theory of Endogenous Coalition Structures" Games and Economic Behavior 26, 1999, pp. 286-336.

[17] Rogerson, Richard, Robert Shimer, and Randall Wright "SearchTheoretic Models of Labor Market: A Survey" Journal of Economic Literature 43, pp. 959-988. 
[18] Roth, Alvin E. "The Evolution of the Labor Markets for Medical Interns and Residents: A Case Study in Game Theory" Journal of Political Economy 92, 1984, pp. 991-1016.

[19] Roth, Alvin E., and Marilda Sotomayor Two-Sided Matching: A Study in Game-Theoretic Modeling and Analysis Cambridge Univ. Press, 1990.

[20] Roth, Alvin E., and Xiaolin Xing "Jumping the Gun: Imperfections and Institutions Related to the Timing of the Market Transactions" American Economic Review 84, September 1994, pp. 992-1044.

[21] Shapley, Lloyd S., and Martin Shubik "The Assignment Game I: The Core" International Journal of Game Theory 1, 1971, pp. 111-130.

[22] Shimer, Robert "The Assignment of Workers to Jobs in an Economy with Coordination Frictions" Journal of Polotical Economy 113, pp. 996-1024. 